To appear in R. Kager, J. Pater \& W. Zonneveld (eds) Fixing priorities: Constraints in phonological acquisition. CUP.

\title{
Input Elaboration, Head Faithfulness and Evidence for Representation in the Acquisition of Left-edge Clusters in West Germanic
}

\author{
Heather Goad ${ }^{1}$ and Yvan Rose ${ }^{1,2}$ \\ McGill University $^{1}$ and University of California, Berkeley ${ }^{2}$
}

June 2001

\section{Preliminaries ${ }^{1}$}

Several recent investigations of the development of left-edge clusters in West Germanic languages have demonstrated that the relative sonority of adjacent consonants plays a key role in children's reduction patterns (e.g. Fikkert 1994, Gilbers \& Den Ouden 1994, Chin 1996, Barlow 1997, Bernhardt \& Stemberger 1998, Gierut 1999, Ohala 1999, Gnanadesikan this volume). These authors have argued that, for a number of children, at the stage in development when only one member of a left-edge cluster is produced, it is the least sonorous segment that survives, regardless of where this segment appears in the target string or the structural position that it occupies (head, dependent, or appendix). To briefly illustrate, while the more sonorous $/ \mathrm{S} / 2$ is lost in favour of the stop in /S/+stop clusters, /S/ is retained in /S/+sonorant clusters; similarly, the least sonorous stop survives in both /S/+stop and stop+sonorant clusters, in spite of the fact that it occurs in different positions in the two strings. To account for reduction patterns such as these, a structural difference between /S/-initial and stop-initial clusters need not be assumed. This would seem to fare well in view of much of the recent constraint-based literature which de-emphasises the role of prosodic constituency in favour of phonetically-based explanations of phonological phenomena (see e.g. Hamilton 1996, Wright 1996, Kochetov 1999, Steriade 1999, Côté 2000).

In this paper, we focus on a second set of reduction patterns for left-edge clusters, one which is not addressed in most of the sonority-based literature on cluster reduction in child language (L1): these patterns reveal a preference for structural heads to survive. For example, while the stop is retained in clusters of the shape /S/+stop and stop+sonorant, it is the sonorant that survives in $/ \mathrm{S} /+$ sonorant clusters. The only sources that we have found where explicit reference is made to the retention of heads are Spencer (1986), who reanalyses Amahl's data

1. An earlier version of this paper was presented at the 1st North American Phonology Conference, Concordia University, Montréal. We would like to thank the audience for questions and comments. We would also like to thank Angela Carpenter, Della Chambless, Suzanne Curtin, Janet Grijzenhout, John Matthews, Joe Pater, and Wim Zonneveld for comments that greatly improved the paper. This research was supported by grants from FCAR and SFB (to H. Goad), from SSHRC (to G.L. Piggott and H. Goad), as well as by a SSHRC doctoral fellowship (to Y. Rose). The authors can be reached at: hgoad@po-box.mcgill.ca and yrose@mac.com.

2. We use the symbol /S/ as a cover for segments which will be analysed as left-edge appendices below. For the most part, /S/ corresponds to /s/ in English and Dutch and to / $/$ in German, the three languages under investigation. Further details are provided in Sections 2 and 4. 
(from Smith 1973) within the context of non-linear phonology, and Gilbers \& Den Ouden (1994), who nonetheless appear to reject a head-based approach at the end of their paper in favour of one based on sonority. Not surprisingly, reference to heads is also absent from the L1 literature which predates the development of non-linear phonology, when the syllable was not widely accepted as a formal constituent (following Chomsky \& Halle 1968). For example, although Amahl's grammar shows a preference for the maintenance of heads, Smith (1973) appeals to sonority in his discussion of cluster reduction. ${ }^{3}$

In order to provide a unified account for both patterns of cluster reduction, we adopt the position that the theory of syllable structure must encode a formal difference between /S/-initial clusters and obstruent-initial clusters more generally, ${ }^{4}$ where $/ \mathrm{S} /$ is represented as an appendix, as was standardly assumed in the literature on non-linear phonology (see below). We will demonstrate further that constraints must make explicit reference to heads of syllable constituents; specifically, the constraint MAXHEAD(ONSET) will play a crucial role in our analysis.

This approach entails that adult inputs are fully prosodified. However, full prosodification requires knowledge of the structures that are permitted in the target language. Accordingly, we propose that children's inputs are initially prosodified for simplex onsets and rhymes/nuclei, that is, for heads of sub-syllabic constituents only. While there is often a correlation between the head of a left-edge cluster and low sonority, we demonstrate that heads cannot be determined solely on the basis of relative prominence; distributional evidence must be factored in and understanding this evidence requires knowledge that is relatively sophisticated. We propose that children initially make decisions about headedness on the basis of sonority until the distributional facts are understood. We argue that it is for this reason that two patterns of cluster reduction are observed in the acquisition data, what we will henceforth call the sonority pattern and the head pattern.

The paper is organised as follows. In Section 2, we introduce the two patterns of cluster reduction under investigation. The data on which we focus are drawn from children learning three West Germanic languages: English, German and Dutch. We turn in Section 3 to our assumptions about acquisition in the context of Optimality Theory (OT), the framework in which our analysis is couched. Our central point will be to demonstrate that the acquisition of an OT grammar involves two components: (i) the elaboration of inputs, and (ii) constraint re-ranking. Our focus will primarily be on the former, specifically on the development of prosodic structure. In Section 4, we turn to an investigation of sub-syllabic structure in West Germanic. We motivate representations for various cluster types and go through the evidence that children require in order to achieve target-like syllabification of these clusters. As will be seen in Section 5, for clusters

3. Smith states that /s/+sonorant clusters are exceptions to the pattern that the least sonorous member is retained, as /s/ is always deleted 'despite its inherent prominence' (p. 166). In discussing the same type of data, Ingram (1989: 32) states that 'deletion of the marked member' is the strategy most commonly observed in children's cluster reductions, but no definition of markedness is provided.

4. Henceforth, we use the term obstruent to refer to all obstruents with the exception of /S/. 
whose structural head corresponds to the least sonorous segment, a single pattern of cluster reduction is observed in the acquisition data. However, when the head does not correspond to what is least sonorous in the adult grammar, namely in /S/+sonorant clusters, patterns of variation are observed across children; indeed, we will argue that the distinction between the sonority and head patterns arises from this mismatch between relative prominence (low sonority) and structural headedness. We demonstrate in Section 5.1 that the head pattern can be accounted for if target-like inputs are posited, that is, highly-articulated representations where obstruent-initial clusters are organised as branching onsets while /S/-initial clusters involve appendix licensing. The sonority pattern, by contrast, arises from less articulated inputs; only heads of sub-syllabic constituents are specified, where heads are defined by low sonority alone. In Section 5.2, we provide the necessary constraints for the analysis. As will be seen, one of these constraints, MAXHEAD, requires that inputs be fully prosodified. In order to establish the viability of this approach beyond accounting for children's cluster reduction, we briefly demonstrate in Section 5.3 that this approach makes the right predictions when confronted with data from adult grammars as well, in particular, from one dialect of Brazilian Portuguese. Section 5.4 shows that, for both patterns of cluster reduction, undominated structural well-formedness constraints yield outputs with simplex onsets and rhymes/nuclei only, the unmarked syllable shape provided by Universal Grammar (hereafter, $\mathrm{UG})$. In Section 6, we turn to the syllabification of $/ \mathrm{Sr} / \mathrm{clusters}$ which, of the three languages under investigation, are only tolerated in German (see note 11 on Dutch and English). Following from Section 4 where we argue that the representation of $/ \mathrm{r} /$ makes $/ \mathrm{Sr} /$ clusters marked as appendix-initial structures, we demonstrate in Section 6 that Annalena, the German-speaking child from whom our data are drawn, initially analyses them as branching onsets. For completeness, in Section 7, we attempt a strictly linear analysis of the head pattern, that is, one which does not exploit syllable-internal constituency but, instead, stems from the observation that (strident) fricatives emerge late in acquisition. We demonstrate that such an approach cannot lead to a satisfactory analysis when confronted with data from children like Amahl. A brief conclusion is provided in Section 8 .

\section{Patterns of cluster reduction}

As mentioned in the introduction, at the point when left-edge clusters are produced as a single segment, several scholars have remarked that the segment which survives is determined by relative prominence: the least sonorous consonant is retained, as can be seen from the first column in (1). ${ }^{5}$ This represents the sonority pattern of cluster reduction. Children who unambiguously display this pattern are listed in the second column by language. ${ }^{6}$ Age ranges are given in

5. The label /S/+obstruent in (1) is used throughout the paper instead of /S/+stop, as Dutch permits /s $\chi /$ (see further Section 4.2). (All three languages also contain /sf/, but it is restricted to a handful of low-frequency loans.) 
parenthesis (note that Subject 25 is language-delayed). The age ranges provided in (1), as well as those in (3), are conservative; they represent the period of time for which a given child displayed all three of the substitution patterns listed in the first column. A subset of these patterns was attested before the dates provided and, for some children, after these dates as well. Note, finally, that concerning the Dutch children, because few forms are provided by Fikkert for a given child at any particular point in time, it is difficult to get a clear sense of the beginning and end points for the stages described in (1) and (3). The classification of children into patterns and the age ranges provided are therefore drawn from the tables that Fikkert provides in Appendix D (pp. 318-329).

Sonority pattern:

Substitution patterns: Children:

Sources:

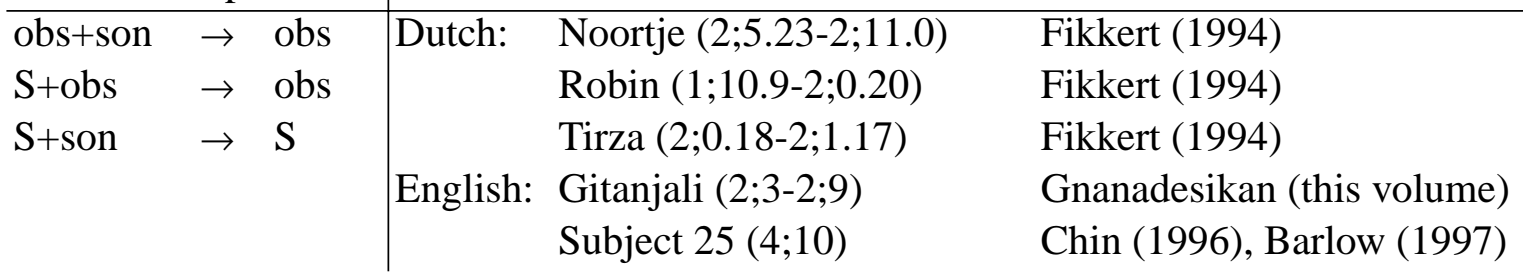

Representative data from Gitanjali and Robin are provided in (2). (All forms are transcribed as in the original sources.) Empty cells represent gaps for the particular cluster or segment type in a given language. ${ }^{7}$ As can be seen, the least sonorous segment is preserved for each cluster type, regardless of its position in the target string. ${ }^{8}$ For Gitanjali, the [p]-initial outputs for 'twinkle' and 'quite' and the [f]-initial outputs for 'smoke' and 'sweater' arise through coalescence (see Gnanadesikan this volume); as features from the least sonorous consonants survive, these forms are consistent with the sonority pattern as well. Coalescence also seems to be responsible for Robin's [f]-initial output for [zv]aaien. The consonants that survive from Robin's clusters in ver[st]opt and [sl]apen, [p] and [f], appear to be due to consonant harmony; importantly, in both

6. While Fikkert mentions the important role played by sonority in cluster reduction, only three of the nine children for whom she provides summaries in her Appendix D (see below in the text) are listed in (1), as these are the only subjects whose outputs unambiguously support the sonority pattern. As we will see shortly, the crucial difference between the sonority and head patterns rests with the treatment of /S/+sonorant clusters. However, all of the Dutch children in Fikkert's study treat /sl/ and /zv/ in the same manner as fricative-initial clusters. (The same probably holds true of English-speaking Joan for /sl/; see note 9 .) Thus, the only potential difference between the sonority and head patterns rests with the treatment of /S/+nasal clusters. Fikkert points out (p. 92) that clusters of this shape are rarely attempted by Dutch children. (A similar observation is made by Lohuis-Weber \& Zonneveld 1996, note 21.) Indeed, two of her subjects (Jarmo, Elke) never attempt clusters of this shape and some avoid /S/+nasal until too late in development; thus, we cannot tell from their outputs which reduction pattern was favoured. In Section 5.1, we will provide an explanation for the treatment of $/ \mathrm{sl} /$ as fricative-initial.

7. Regarding the gap for /Sk/, Dutch - as well as German - has a number of /sk/-initial loans (German no longer has $/ \int \mathrm{k} /$-initial words). Some of these loans are high frequency and will no doubt be present in the early input to which children are exposed. However, we have no information on their acquisition in either language, and so they will not be considered further.

8. This assumes that fricatives are more sonorous than stops, a proposal which is supported on phonetic grounds but which has been challenged on phonological grounds (see e.g. Hall 1992 and Wiese 1996 on German). As will be seen in Section 5.1, the phonetic difference between the sonority value of stops and fricatives also plays a role in our analysis of the construction of inputs by children who follow the sonority pattern. 
cases, the non-harmonised counterparts, $[\mathrm{t}]$ and $[\mathrm{s}]$, correspond to the least sonorous member of the cluster.

(2) Sonority pattern data:

\begin{tabular}{|c|c|c|c|c|c|c|}
\hline & \multicolumn{2}{|l|}{ Gitanjali } & \multicolumn{3}{|l|}{ Robin } \\
\hline & & Output & Gloss & Output & Orthog/Target & Gloss \\
\hline \multirow[t]{14}{*}{ obs+son } & pl-bl & [piz] & 'please' & [puint] & [pl]ons & 'splash' \\
\hline & kl-gl & [kin] & ‘clean’ & (no data) & & \\
\hline & fl-vl & (no data) & & ['fi: $\chi$ 'da $\chi$ ] & [vl]iegtuig & 'aeroplane' \\
\hline & $\chi 1$ & & & ['ka,kain] & {$[\chi 1]$ ijbaan } & 'slide' \\
\hline & pr-br & [fibcy $]$ & 'umbrella' & [bat] & [br]and & 'fire' \\
\hline & $\operatorname{tr}-d r$ & {$[\mathrm{dp}]$} & 'draw' & ['tıkə] & [dr]inken & 'to drink' \\
\hline & $\mathrm{kr}-\mathrm{gr}$ & [go] & 'grow' & ['mi:kə'fo:n] & mi[kr]ofoon & 'microphone' \\
\hline & fr-vr & {$[\mathrm{f} \varepsilon \mathrm{n}]$} & 'friend' & {$[\mathrm{fa} \chi]$} & [vr]acht & 'load' \\
\hline & $\theta \mathrm{r}$ & (no data) & & & & \\
\hline & $\int \mathrm{r}$ & (no data) & & & & \\
\hline & $\chi^{r}$ & & & [suint] & {$[\chi \mathrm{r}]$ ond } & 'ground' \\
\hline & & & & ['kıpo] & [kn]uppel & 'club' \\
\hline & tW-dW & [pikəw] & 'twinkle' & (no data) & & \\
\hline & $\mathrm{kW}$ & [payt] & 'quite' & (no data) & & \\
\hline \multirow[t]{4}{*}{ S+obs } & $\mathrm{Sp}$ & [bun] & 'spoon' & ['pılə'ti:k] & [sp]eel-o-theek & 'playground' \\
\hline & St & [da: $]$ & 'star' & [purft] & ver[st]opt & ‘hidden’ \\
\hline & Sk & [gay] & 'sky' & & & \\
\hline & $S \chi$ & & & [zo:] & {$[\mathrm{s} \chi] \mathrm{ool}$} & 'school' \\
\hline \multirow[t]{4}{*}{ S+son } & S1 & [sip] & 'sleep' & ['fa:pə] & [sl]apen & 'to sleep' \\
\hline & $\mathrm{Sm}$ & [fok] & 'smoke' & (no data) & & \\
\hline & $\mathrm{Sn}$ & [so] & 'snow' & ['surpi:] & [sn]oepje & 'sweet' \\
\hline & SW & {$[\mathrm{f} \varepsilon \mathrm{D} \Lambda]$} & 'sweater' & ['fa:jə] & [zv]aaien & 'to sway' \\
\hline
\end{tabular}

Previous studies have shown that the sonority pattern of cluster reduction can be analysed without drawing a formal distinction between obstruent-initial and /S/-initial clusters; indeed, no syllable-internal constituency need be assumed at all (e.g. Barlow 1997, Bernhardt \& Stemberger 1998, Gnanadesikan this volume). However, there is a second pattern of cluster reduction, what we refer to as the head pattern, which seems to require reference to syllable-internal structure: it is the head of the onset constituent that survives, as can be observed in (3). ${ }^{9}$ Heads are underlined.

9. As alluded to in note 6 , for Joan, definitive evidence for the head pattern is found in /s/+nasal reductions only. (/sw/ undergoes fusion to [f], which is compatible with both patterns of cluster reduction.) When /sl/ is attempted at $2 ; 1$, it is realised as [s], not as [1]. However, target /l/ is realised as [z] at this stage; thus, we cannot be entirely sure about whether output $[\mathrm{s}]$ from /sl/ is preservation of /s/ or whether it arises from fusion of /s/ and /1/. For Naomi, evidence for the head pattern is also limited to / $/+$ nasal; she does not attempt / $1 /$ (Janet Grijzenhout personal communication). 
(3) Head pattern:

Substitution patterns: Children:

\begin{tabular}{lll|lll}
\hline$\underline{\text { obs}}+$ son & $\rightarrow$ & $\underline{\text { obs }}$ & Dutch: & Tom $(1 ; 6.11-1 ; 6.25)$ & Fikkert (1994) \\
$\mathrm{S}+\underline{\mathrm{obs}}$ & $\rightarrow$ & $\underline{\mathrm{obs}}$ & & Robin $(2 ; 1.9-2 ; 3.24)$ & Fikkert (1994) \\
$\mathrm{S}+\underline{\mathrm{son}}$ & $\rightarrow$ & $\underline{\text { son }}$ & & Catootje $(2 ; 0.6)$ & Fikkert (1994) \\
& & & English: & Joan $(1 ; 10-2 ; 1)$ & Velten (1943) \\
& & Amahl $(2 ; 2-2 ; 6)$ & Smith (1973) \\
& & German: & Annalena $(1 ; 4-1 ; 9)$ & Elsen (1991) \\
& & Naomi $(1 ; 4.26-1 ; 7.27)$ & Grijzenhout \& Joppen (in press)
\end{tabular}

The table in (4) provides representative data from Amahl and Annalena. ${ }^{10}$ This pattern is characterised by reduction of a cluster to the head of the target structure, which does not necessarily correspond to the least sonorous segment of the string. We can observe in (4a) that for left-headed clusters, it is the initial obstruent that survives. In (4b) and (4c), by contrast, the constituent head is the second member of the cluster, and it is this consonant that survives, regardless of its relative sonority. While Amahl's [w]-initial outputs for 'flag' and 'friend' in (4a) may appear to interrupt the pattern, [w] is his substitute for /f/, not for /1,r/; in non-harmonising contexts, /1,r/ are realised as liquids at this stage in development (cf. Goad 1997). Note as well that in 'three' and 'Shreddies', [d] is Amahl's substitute for both $/ \theta /$ and $/ \mathrm{f} /$ in initial position.

For completeness, we have included the /S/+rhotic data in (4d), as this cluster is licit in German. ${ }^{11}$ However, the acquisition of $/ \mathrm{Sr} /$ is complicated, which is why it is listed separately from the other S+sonorant clusters and why the head of the cluster has not been underlined. On the basis of what was observed in (4c), we would have expected /r/ to be retained in (4d). Counter to expectation, though, it is /S/ that survives. /S/ is realised by Annalena most often as $[\theta, ð]$ at this stage in development; /r/, on the other hand, surfaces as [в] or [х], aside from a few cases of [?,h] and [g], the latter due to consonant harmony. We delay further discussion of / $\mathrm{Sr} /$ until Sections 4.3 and 6.

10. [b, do g̊] represent voiceless unaspirated lenis stops in Amahl's outputs (Smith 1973: 37); overdots in Annalena's forms indicate that a consonant is ambisyllabic (Elsen 1991: 10).

11. This implies that $/ \mathrm{Sr} /$ is illicit in Dutch and English. As concerns Dutch, /s $\chi \mathrm{r} /$ is realised as [sr] by many speakers (see Waals 1999: 23 for acoustic evidence). If this reflects a reanalysis of /s $\chi \mathrm{r} /$, then $/ \mathrm{Sr} /$ clusters may be present in this language as well. However, unlike with German, we have no information on the acquisition of [sr] in Dutch. We will henceforth consider this cluster to be ill-formed in Dutch, although nothing rests on this. As concerns English, [ $\int \mathrm{r}$ ] is not /S/-initial but is, instead, analysed as a branching onset, as can be seen from its location in (2) and (4). See Sections 4.1 and 4.3 for further discussion. 
(4) Head pattern data:

\begin{tabular}{|c|c|c|c|c|c|c|}
\hline & \multicolumn{2}{|l|}{ Amahl } & \multicolumn{3}{|c|}{ Annalena } \\
\hline & & Output & Gloss & Output & Orthog/Target & Gloss \\
\hline \multirow{12}{*}{ a. $\underline{\text { obs}}+$ son } & pl-bl & [be:t] & 'plate' & [bumə] & [bl]ume & 'flower' \\
\hline & kl-gl & [g̊ok] & 'clock’ & {$\left[\mathrm{k} \overline{\mathrm{a}}^{\mathrm{I}} \mathrm{n}\right]$} & [kl]ein & 'small' \\
\hline & $\mathrm{fl}$ & [wæg̊] & ‘flag' & [fikə] & [fl]iege & ‘fly’' \\
\hline & pr-br & [bed] & 'bread' & [bauxst] & [br]auchen & 'to need' \\
\hline & $\operatorname{tr}-\mathrm{dr}$ & [dei] & ‘tray' & [daubc] & [tr]aube & 'grape' \\
\hline & kr-gr & [g̊ot] & 'cross' & [gif] & [gr]iff & ‘grip’ \\
\hline & fr & [wend] & 'friend' & {$[\operatorname{vox} \theta]$} & {$[\mathrm{fr}] \mathrm{osch}$} & 'frog' \\
\hline & $\theta \mathrm{r}$ & [di: & 'three' & & & \\
\hline & $\int \mathrm{r}$ & [dedi:] & 'Shreddies' & & & \\
\hline & $\mathrm{kn}$ & & & {$[\overline{\mathrm{k}} \mathbf{1}]$} & [kn]ie & 'knee' \\
\hline & tW-dW & [daif] & 'twice' & & & \\
\hline & $\mathrm{kW}$ & [g̊i:m] & 'queen' & {$[g \bar{a} \mathrm{k}]$} & {$[\mathrm{kv}] \mathrm{ark}$} & 'quark' \\
\hline \multirow[t]{3}{*}{ b. $\mathrm{S}+\underline{\mathrm{obs}}$} & $\mathrm{Sp}$ & \begin{tabular}{|l|} 
[baidə] \\
\end{tabular} & 'spider' & [pıg̊วl] & 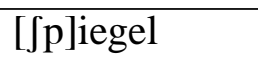 & 'mirror' \\
\hline & St & [dif] & 'stiff' & [dainə] & {$\left[\int \mathrm{t}\right] \mathrm{ein}$} & 'stone' \\
\hline & Sk & [g̊ip] & 'skipping' & & & \\
\hline \multirow[t]{4}{*}{ c. $\mathrm{S}+\underline{\mathrm{son}}$} & Sl & {$[1 \wedge \mathrm{g}]$} & 'slug' & [lāfə] & [ 1 l]afen & 'to sleep' \\
\hline & $\mathrm{Sm}$ & {$[\mathrm{mor}]$} & 'small' & [mis̊on] & {$\left[\int \mathrm{m}\right]$ eißen } & 'to throw' \\
\hline & $\mathrm{Sn}$ & [nird] & 'sneezed' & [nel] & {$\left[\int \mathrm{n}\right] \mathrm{ell}$} & 'quick' \\
\hline & SW & [win] & 'swing' & [vain] & {$\left[\int v\right]$ ein } & 'pig' \\
\hline d. S+rhotic & $\mathrm{Sr}$ & & & [Öıə] & {$\left[\int \mathrm{r}\right]$ eiben } & 'to write' \\
\hline
\end{tabular}

Similarities and differences between the head and sonority patterns can be seen most clearly from the summary table provided in (5).

(5) Sonority pattern versus head pattern:

$\begin{array}{llll}\text { a. obstruent+sonorant } & \begin{array}{l}\text { Sonority pattern: } \\ \text { obstruent }\end{array} & \begin{array}{l}\text { Head pattern: } \\ \text { obstruent } \\ \text { obstruent }\end{array} \\ \text { b. S+obstruent } & \text { obstruent } \\ \text { c. S+sonorant } & \text { S } & \text { Sonorant }\end{array}$

The two patterns diverge for /S/-initial clusters that rise in sonority, (5c). This is precisely where there is a mismatch between the head of the cluster and the segment that is least sonorous. This mismatch precludes any comprehensive analysis of the head pattern which relies on constraints that refer to relative sonority.

We will provide a unified account for both the head and sonority patterns in Section 5, one which focuses on the retention of heads in both cases. We must first discuss our assumptions 
about acquisition (Section 3) and provide the structures that we adopt for obstruent-initial and /S/initial clusters in the target grammars (Section 4).

3 Acquisition of an optimality-theoretic grammar

\subsection{General assumptions}

As mentioned in the introduction, we adopt the framework of Optimality Theory (OT) (Prince \& Smolensky ms), with the more recently developed view that faithfulness constraints are defined under Correspondence Theory (McCarthy \& Prince 1995). Within OT, the linguistic competence of a speaker comprises a universal set of hierarchically-ranked and thus violable constraints. Different constraint rankings yield different grammars; therefore, variation observed across languages, or across stages in the acquisition of a single language, is accounted for by alternate rankings of this finite set.

When applied to acquisition, the basic premises of OT are compatible with Pinker's (1984) continuity assumption: child and adult languages are not formally different in the sense that early grammars, at every stage in their development, reflect possible adult grammars. Thus, we contend that all systematic alternations observed in child data must be analysed using constraints that are independently motivated in adult grammars, and further, we adopt the strong position that all constraints are innate (Gnanadesikan this volume). Consequently, (i) children's grammars contain no more than adult grammars, that is, there are no child-specific constraints (for a different view, see Pater 1997); and (ii) they contain no less than adult grammars, that is, there is no emergence of constraints or of the primitives, structures, and operations that they refer to (Goad in press).

To a great extent, children's early grammars differ from adult languages in predictable ways. Perhaps the most obvious of these is that children's early outputs are prosodically unmarked. For example, there is an initial preference for CV syllables, yielded primarily by segmental deletion. As patterns such as these are systematically observed across children, they must reflect early grammatical organisation. In the OT literature on acquisition, this is typically expressed in terms of preferred constraint rankings where markedness constraints initially outrank faithfulness constraints (Demuth 1995, Smolensky 1996, Gnanadesikan this volume, inter alia; cf. Hale \& Reiss 1998). This view formally expresses the observations of Jakobson (1941/68) and Stampe (1969) that early grammars reflect what is cross-linguistically unmarked. A crucial part of the acquisition process therefore involves re-ranking of constraints, on the basis of positive evidence (Chomsky 1981), in order to allow for the production of more marked structures when these are found in the target language. 


\subsection{Full specification of inputs}

Most of the OT literature on acquisition has focused on the child's ranking at a particular stage in development or on re-ranking across stages over time. Less attention has been devoted to the shapes of early inputs. At the segmental level, it is typically assumed, following Smith (1973), that children's inputs are in essential respects identical to adult outputs (modulo perceptual problems; see Macken 1980). In its strongest interpretation, this means that children's inputs are not underspecified, nor are they in any way impoverished. In the OT literature, the discussion in Hale \& Reiss (1998) is particularly clear in this respect. They state that 'children have access to the full set of universal features in constructing URs and that they store URs fully and accurately specified, according to what they hear in the target language' (p. 660). Indeed, if Lexicon Optimization guides acquisition from the outset (Prince \& Smolensky ms), learners are forced to this: they are reconciled to one input-output pairing, that where faithfulness is maximally respected, except in the face of alternations. ${ }^{12}$ In short, children's segmental inputs must be fully specified.

At the level of prosodic structure, the literature is less explicit (but see Pater this volume). However, if constraints express faithfulness to prosodic heads (e.g. Alderete 1995, Pater 2000, Itô et al ms, McCarthy ms), then inputs must be fully prosodified. We provide empirical evidence in favour of this view from Brazilian Portuguese in Section 5.3. As far as the learner is concerned, once faithfulness constraints take prosodic constituents as arguments, then Lexicon Optimization must guide the learner to select appropriate inputs at all levels of representation, both segmental and prosodic (contra Inkelas ms). Accordingly, children's inputs must be fully prosodified. However, as mentioned earlier, since adult-like prosodification requires an understanding of the structures that are tolerated in the target language, children's inputs can only be prosodified to the extent that they reflect the knowledge that learners have at a particular stage in development. Throughout the course of acquisition, then, inputs become more elaborate as the structural relations that hold across segments in the target language come to be understood. ${ }^{13}$

In short, our central point is that the acquisition of an OT grammar involves two components: (i) the elaboration of inputs, and (ii) constraint re-ranking. And while most research has focused on the latter, we focus primarily on the former. Indeed, our account of the two patterns of cluster reduction will be built around the elaboration of inputs. Our analysis will rely on the following premises: (i) syllables are highly-articulated structures (contra Kahn 1976, and what is explicit or implied in the phonetically-motivated constraint-based approaches of Hamilton

12. This is in spite of Richness of the Base which contends that all inputs are possible, as the burden of selecting the correct output rests solely with constraint ranking (Prince \& Smolensky ms). We agree with Hale \& Reiss (1998) that Richness of the Base is concerned with OT as a computational system, and not with real language learners.

13. This is opposite to the view espoused by Gnanadesikan (this volume). She proposes that the child's inputs are specified for syllable structure, although she does not accept that this holds true of the target grammar. The child first builds inputs on the basis of adult outputs, that is, from forms which are fully prosodified. Throughout the course of acquisition, these representations must be pruned back. 
1996, Wright 1996, Kochetov 1999, Steriade 1999, Côté 2000, and others); (ii) obstruent-initial clusters are left-headed branching onsets, while /S/-initial clusters begin with an appendix; and (iii) the appendix-initial structure holds for /S/-initial clusters that rise in sonority, not only for those with flat or falling sonority (contra Giegerich 1992, Hall 1992, Fikkert 1994, and others). In the following section, we discuss these premises in greater depth.

\section{Representations}

As already mentioned, an analysis of the sonority pattern can be provided without reference to syllable-internal structure: what survives can be determined solely by a prohibition on consonant sequencing and by a family of constraints that reflect relative prominence in the acoustic signal. The head pattern, by contrast, cannot be so analysed. It requires that obstruentinitial clusters be distinguished from /S/-initial clusters on structural grounds.

Outside of acquisition, the clearest evidence of the need for two types of structures can be found by observing that the presence or absence of obstruent-initial clusters in a language is independent of the presence or absence of /S/-initial clusters. A comparison of (6a) and (6b) reveals that Spanish, for example, contains only the former structure, while Acoma (Miller 1965) allows only for the latter.

(6) Four-way typology:

\begin{tabular}{|l|c|c|}
\hline Languages & Obstruent-initial & /S/-initial \\
\hline a. Spanish & yes & no \\
\hline b. Acoma & no & yes \\
\hline c. Maori, Japanese & no & no \\
\hline d. German, Dutch, English & yes & yes \\
\hline
\end{tabular}

In Section 2, we observed that early child language resembles languages like Maori and Japanese (6c) in the sense that there are no left-edge clusters present in output representations. Nevertheless, in the three West Germanic languages under investigation (6d), there is ample evidence available that left-edge clusters are tolerated. The child's task is to determine what the appropriate representations are for these clusters.

As can be seen from (7), in the unmarked case, we consider obstruent+liquid clusters to be branching onsets (7a) and /S/-initial clusters to involve a left-edge appendix (7b). These representations are consistent with much of the literature on West Germanic. In particular, the special status assigned to /S/ in at least some /S/-initial clusters has typically been captured by positing that this segment is an appendix or is extrametrical (see e.g. Vennemann 1982, Wiese 1988, Hall 1992 on German; Trommelen 1984, van der Hulst 1984, Kager \& Zonneveld 1985/86, 
Fikkert 1994 on Dutch; Steriade 1982, Levin 1985, Giegerich 1992, Kenstowicz 1994 on English). ${ }^{14}$

As we accept the standard view that segments are organised into prosodic constituents, we also consider all constituents to be headed. The notion of headedness refers to an asymmetrical relation that holds between adjacent elements within or across constituents. Heads have a primacy not accorded to non-heads: (i) they display distributional freedom in the sense that heads can license more melodic content than non-heads, and (ii) non-heads - whether internal or external to the relevant constituent - are dependent for their very existence on the presence of a head. The vertical line linking the skeletal position to $\mathrm{O}(\mathrm{nset})$ in (7) indicates that we consider branching onsets to be universally left-headed (following e.g. Kaye, Lowenstamm \& Vergnaud 1990). In the case of two-member appendix-initial clusters, head status is trivially assigned to the only segment in the onset constituent, that is, to the rightmost member of the cluster. Following from this, we distinguish two types of non-heads: dependents which are constituent-internal, and appendices which are linked to some higher prosodic constituent, in the unmarked case, to the prosodic word (PWd), as we discuss below.

(7) Unmarked syllabification options for left-edge clusters:
a. Branching onset:
b. Appendix+onset:
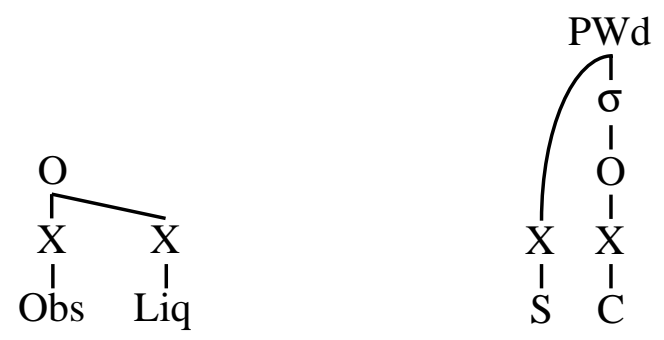

The notion head of onset will play a significant role in our account of L1 cluster reduction. Outside of this context, in Section 5.3, we will provide supporting evidence for this notion from cluster reduction in southeastern Brazilian Portuguese, as well as in German (hypocoristics) and Québec French.

In some languages, syllabification options other than those in (7) will be required. For example, as concerns the structure in (7a), Kaye (1985) has argued that, in Vata, obstruent+liquid strings are syllabified with the liquid in the nucleus. Concerning appendixal /S/, two options are required for West Germanic. While German respects the unmarked option in (7b), Dutch and English require /S/ to be linked to the syllable node in /S/+obstruent clusters. In German, / $/+\mathrm{C}$ clusters occur stem-initially (e.g. be-stehen [bə.fte:.hən] 'insist'), but they do not occur

14. Two alternative options for /S/ at the left edge are as follows: (i) /S/+stop clusters form single (complex) segments (e.g. Fudge 1969, Ewen 1982, Selkirk 1982, van de Weijer 1996, Wiese 1996); and (ii) /S/ is the coda of an emptyheaded syllable (Kaye 1992). We will not address these options further. 
morpheme-internally (see e.g. Hall 1992). / / must therefore link to the PWd. In Dutch and English, by contrast, /s/+C clusters have a wider distribution. Van der Hulst (1984) uses examples such as ek.ster 'magpie' to argue against analyses along the lines of (7b) for Dutch and in favour of one where /s/ is a 'syllable prefix' (contra Trommelen 1984, Fikkert 1994: 51). Similar arguments are made by Zonneveld (1993) and Booij (1995), as well as by Levin (1985) for English. We elaborate on the problem for English as follows. There are many words like con.sta.ble where the rhyme preceding /s/ is binary branching. Given that, with limited exceptions, ternary-branching rhymes are not permitted in English (see esp. Harris 1994), /s/ must be analysed as an appendix to the following syllable.

Clearly, word-internal data are required to determine whether the syllable or PWd is the appropriate host for /S/. If /S/ were linked to the syllable in the unmarked case, the Germanspeaking child would require indirect negative evidence to arrive at the alternative analysis in (7b). We propose, therefore, that association to the PWd is the unmarked case. Positive evidence will then be available for learners to determine that the syllable is the correct host in Dutch and English.

While the typology in (6) demonstrates the need for two different representations for leftedge clusters, (7a) and (7b), it does not address the question of where to draw the line between cluster type. As UG requires branching onsets to rise in sonority, there is little dispute about the correct representations for obstruent+liquid and /S/+stop clusters (but see note 14). ${ }^{15}$ Accordingly, once the child attempts to build structures other than singleton onsets at the left edge, representations for these two cluster types should pose little difficulty: obstruent+liquid clusters fit the ideal profile for a branching onset (Clements 1990), (7a); and a sonority fall or plateau is observed in /S/+obstruent clusters, so the child will realise that /S/ cannot be part of the onset and must instead occupy an appendix position, (7b). In the latter case, the child's analysis will be consistent with the observation that left-edge appendices are limited to /S/ in the unmarked case. ${ }^{16}$ Additional positive evidence for the postulation of these two types of structures is readily

15. The representation in (7a) has been provided as the unmarked structure for obstruent+liquid clusters only. Nasaland glide-final clusters are not included, in spite of the fact that we listed $/ \mathrm{kn} /$ and $/ \mathrm{CW} /$ alongside what are indisputably branching onsets in Section 2. In the case of $/ \mathrm{kn} /$, this was because Dutch and German children who follow the head pattern of cluster reduction retain the stop, not the nasal, consistent with the branching onset analysis. Further, Fikkert (1994) points out that all of the Dutch children go through a stage where $/ \mathrm{kn} /$ clusters are produced as [kl]. The same observation holds for Annalena (Elsen 1991). However, the issues that arise in the syllabification of $/ \mathrm{kn} /$ are complicated; we refer the interested reader to Trommelen (1984) and Kager \& Zonneveld (1985/86) who treat Dutch /kn/ as appendix-initial (see also van der Hulst 1984), and to Hall (1992), Booij (1995), and Wiese (1996) who treat $/ \mathrm{kn} /$ as a branching onset. In the case of $/ \mathrm{CW} /$, these clusters are branching onsets in the languages under consideration. However, the possibility that this reflects the unmarked representation for clusters of this shape has been challenged by Y. Rose (1999). Further, early French learners treat obstruent+liquid clusters differently from obstruent+glide, casting doubt on the branching onset structure as the unmarked analysis for obstruent+glide (see Y. Rose 2000). In the interest of space, we do not consider $/ \mathrm{kn} / \mathrm{and}$ $/ \mathrm{CW} /$ clusters further.

16. Beyond the fact that the coronality of /S/ makes it unmarked on the place dimension, this restriction on the quality of appendices appears to be due to the fact that the stridency of $/ \mathrm{S} /$ makes it audible in all contexts, even when adjacent to a stop. 
available through the child observing that three-member clusters at the left edge are (virtually) always /S/-initial. If UG permits onset constituents to be at most binary, as is standardly assumed, sequences of the shape /S/+stop+liquid must involve a combination of the structures in (7a) and (7b).

One of the greatest difficulties for the linguist lies in determining the appropriate representation for /S/-initial clusters that rise in sonority. In Section 4.2 below, we will provide a number of arguments to demonstrate that, at least in West Germanic, all /S/-initial clusters are syllabified with left-edge appendices. Importantly, then, there is no direct correlation between headedness and some phonetic property (low sonority or low air flow); instead, distributional facts must be taken into consideration. In Section 5.1, we will propose that it is for this reason that these clusters also pose the greatest challenge for the learner. However, based on the data from Amahl and Annalena provided earlier in (4c), where /S/+sonorant $\rightarrow$ sonorant in the head pattern, we hope that the skeptical reader who equates rising sonority with branching onset status can accept that this is the analysis that these two children have arrived at.

\subsection{Place specifications in coronals}

Before we can compare alternative representations for rising sonority /S/-initial clusters, we must briefly consider liquid-final clusters, as one constraint - that which rules out place identity within a branching onset - must be introduced first. This, in turn, will lead to a discussion of the representations that we adopt for coronals.

As can be seen from (8a.i), in all three languages under consideration, stops can freely combine with liquids in branching onsets with one exception: /t/ cannot combine with /1/. (We limit the discussion to voiceless obstruent heads.)

Liquid-final clusters:

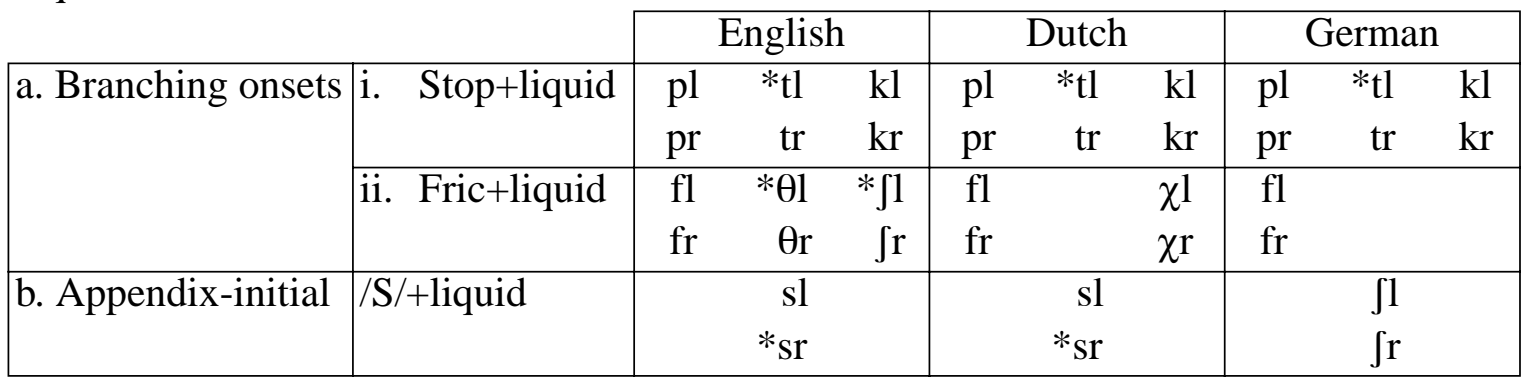

The absence of $* / \mathrm{tl} /$ is typically attributed to a constraint that forbids the two members of a branching onset from agreeing in place, what we have called *PLACEIDENT in (9). The constraint holds for all places of articulation; thus, alongside */tl/, */pw/ is illicit in English, as is */pv/ in Dutch and German. 
*PlaceIdent:

Adjacent consonants within an onset constituent cannot be specified for the same articulator

The restriction on place identity in onsets is widely attested across languages, strongly suggesting that it is the UG unmarked option. Accordingly, the child needs no evidence to rule out clusters of this shape. ${ }^{17}$

Turning to (8a.ii), the ungrammatical branching onsets with fricative heads in the English column provide us with more information on how *PLACEIDENT works. On the one hand, exact identity is not enough to rule out a cluster: dental $/ \theta /$ cannot combine with alveolar $/ 1 /$. At the same time, palato-alveolar $/ \mathrm{J} /$ and post-alveolar $/ \mathrm{r} /$ are not close enough to be ruled out. In order to reconcile these facts, we propose, following Lebel (1998), that *PLACEIDENT targets the level of the articulator node, and not the level of the feature that a given articulator dominates. If all coronals - with the exception of $/ \mathrm{r} /$ - are specified for a Coronal node, the correct results will obtain. See (10). ${ }^{18}$ Importantly, we assume that the representation in (10b) holds, independently of whether $/ \mathrm{r} /$ is articulated as coronal or dorsal. Indeed, in two of the languages under investigation, Dutch and German, both coronal and dorsal variants are attested (see e.g. Booij 1995 on Dutch, Hall 1992 and Wiese 1996 on German).

Place specifications for coronals and $/ \mathrm{r} /$ :
a. /t-d, $\theta-ð, \mathrm{~s}-\mathrm{z}, \int-3, \mathrm{l}, \mathrm{n} /$
b. $/ \mathrm{r} /$

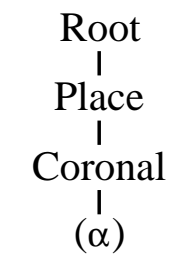

Before we elaborate on the motivation for $/ \mathrm{r} /$ as placeless, let us compare (8a.ii) and (8b) in the context of (9) and (10). /S/+liquid clusters are included in (8) for comparison, but they are not organised as branching onsets (see Section 4.2 for evidence). Undoubtedly, some confusion may arise in a comparison of English and German. In English, /S/ is always realised as /s/, and so / $\mathrm{r} /$ is not appendix-initial but is, instead, organised as a branching onset, (8a.ii). Indeed, branchingonset status of $/ \int /$-initial clusters is what accounts for the ill-formedness of $* / \int 1 /$ in this language,

17. Somewhat surprisingly, children do produce clusters of this type, e.g. Amahl's [tlæmp] 'tramp'. Goad (1996) has argued that, in such cases, the constraint in (9) has not been violated, as Coronal has not yet been projected for [1], evidence for which comes from the behaviour of liquids in consonant harmony. Fikkert (1994: 120-122) provides similar examples from the acquisition of Dutch, e.g. Jarmo's [tlei] 'train'.

18. The representations in (10) reveal that we assume feature geometry. Although this is the case, it is not essential to the point being made. All that is required is for the segments in (10a) to bear Coronal; exactly how this is formally expressed is somewhat tangential. 
as both segments bear a Coronal node, (10a). In German, by contrast, where /S/ is realised as / $/$ /, both $/ \int 1 /$ and $/ \int \mathrm{r} /$ are appendix-initial; the constraint in (9) is thus irrelevant to their wellformedness. The cross-language comparison is further complicated by the fact that, while appendix-initial $/ \int \mathrm{r} /$ is attested in German, the corresponding cluster, */sr/, is illicit in English, as well as in Dutch (see note 11); we will come back to this in Section 4.3.

We return now to furnish additional support for (10b). The representation provided reveals that we consider /r/ to be permanently unspecified for place (see also Rice 1992: 76); it is thus the sonorant counterpart to $/ 2 /$. Such a representation is motivated by the fact that $/ \mathrm{r} /$ behaves asymmetrically in the phonologies of several languages. For example, it is the only consonant that cannot undergo (partial) gemination in Japanese (Mester \& Itô 1989: 275), the only non-labial consonant that cannot host palatalization in Muher (S. Rose 1997), and it behaves asymmetrically in the L1 consonant harmony patterns observed in Québec French (Y. Rose 2000). In the underspecification literature of the 1980s and 1990s, facts such as these were commonly captured through /r/ being minimally placeless and possibly featureless in a number of languages. Importantly, the asymmetric behaviour that $/ \mathrm{r} /$ displays is observed independently of how it is articulated, as expected from the representation in (10b).

One can conclude from the discussion thus far that we draw a formal distinction between phonological representation and phonetic interpretation, standard in the 1980s and early 1990s, but counter to a commonly observed trend in the OT literature. Motivating this distinction is far beyond the scope of the present paper. We merely demonstrate the advantages of treating $/ \mathrm{r} /$ as articulatorless in the languages under present discussion. The most obvious advantage of adopting the representation in (10b) is that it enables us to account for the place facts observed in (8a): coronal-initial branching onsets which contain /r/ as their dependent will not violate *PLACEIDENT in (9). Beyond this, however, the representation in (10b) will also factor into our analysis of the asymmetries in the inventories of /S/-initial clusters provided in (8b) above; in particular, it will play a central role in our explanations for: (i) why /sl/ is licit in English and Dutch while */sr/ is not (Section 4.3), and (ii) why Annalena incorrectly analyses German / $\mathrm{r} / \mathrm{as}$ a branching onset (Section 6).

\subsection{Rising sonority /S/-initial clusters}

Now that we have provided some background on the properties that characterise branching onsets, we are in a position to compare alternative analyses for rising sonority /S/-initial clusters. We adopt the position of Trommelen (1984), van der Hulst (1984) and Kager \& Zonneveld (1985/86) that all /S/-initial clusters (at least in West Germanic) contain appendices. In the

literature, however, this point of view is often not accepted. Indeed, a number of scholars have proposed that $/ \mathrm{S} /+$ sonorant clusters are instead organised as branching onsets (see e.g. Giegerich 
1992 on English, Hall 1992 on German, Fikkert 1994 on Dutch). The most common argument in favour of this alternative is that, in contrast to /S/+obstruent clusters, these sequences abide by the requirement that branching onsets rise in sonority. In spite of their rising sonority, we will provide three arguments in favour of the appendix-initial analysis for /S/+sonorant clusters: the syllabification of /S/-initial clusters in intervocalic position in Dutch, the absence of place identity effects in /S/+coronal clusters, and the lack of place restrictions on nasals in /SN/ clusters. ${ }^{19}$

We begin with intervocalic /S/-initial clusters in Dutch. Trommelen (1984) and Kager \& Zonneveld (1985/86) have noted that/S/+obstruent clusters are syllabified as heterosyllabic in this position, e.g. pás.ta 'paste', és.ki.mo 'eskimo', in contrast to branching onsets, e.g. lé..pra, *lép.ra 'leprosy', zé:.bra, *zéb.ra 'zebra'. Notably, /s/+sonorant clusters pattern with /s/+obstruent clusters in this respect, e.g. prís.ma 'prism', ós.lo 'Oslo'. This strongly suggests that all /s/-initial clusters are analysed in the same fashion, differently from how branching onsets are syllabified.

Turning to the second argument, we have seen that *PLACEIDENT in (9) rules out strings of segments which bear the same articulator node within the onset constituent. Let us look at /S/initial clusters that are followed by coronals in this context. As it is generally accepted that /S/+obstruent clusters are represented as appendix+onset structures, /St/ clusters should not be subject to (9). This is indeed the case: /st/ is well-formed in English and Dutch, as is / $\mathrm{t} t /$ in German. However, the absence of place identity effects is also observed with /S/+sonorant clusters: /sl/ and /sn/ are licit in English and Dutch, as are / $1 /$ and / $\mathrm{n} / \mathrm{in}$ German. If these clusters were organised as branching onsets, they would violate *PLACEIDENT in (9). This would seem to be strong evidence that they are instead syllabified with initial appendices. Perhaps, however, place identity is only apparent in these cases; if /S/ were analysed as placeless, then /S1,Sn/ clusters would not violate the constraint in (9) and rising sonority clusters could be represented as branching onsets. While this approach would provide us with an explanation for why, under the branching onset analysis, /S1/ and /Sn/ are licit, it will not enable us to account for the absence of /Sr/ in English and Dutch. As a branching onset, this cluster should be well-formed and yet, it is not, a fact which we return to in Section 4.3. We thus reject the placeless /S/ option as spurious and contend that $/ \mathrm{S} /+$ coronal strings are licit because, as appendix-initial, they are not subject to *PlaceIdent in (9).

We consider finally the evidence from /S/+nasal strings. Across languages, nasal dependents in branching onsets are restricted to $/ \mathrm{n} /$, if not universally, then at least in the vast majority of languages that permit such clusters (see Humbert 1997 for related discussion). Indeed, this

19. Other arguments are available which, in the interest of space, we do not provide; on English, for example, see Kaye (1992) which includes discussion of the psycholinguistic evidence obtained by Treiman, Gross \& Glavin (1992). Additional arguments appeal to gaps in the expected inventory of clusters; if rising-sonority /S/-initial clusters were branching onsets, the child would have to use indirect negative evidence to come to the conclusion that this analysis is unavailable for certain combinations of segments, counter to expectation. 
restriction holds of languages with large inventories of $\mathrm{CN}$ clusters like Greek, as well as in languages like Dutch and German. If /S/+nasal clusters were organised as branching onsets, we could not account for the fact that $/ \mathrm{Sm} /$ is well-formed in the languages under present investigation. If, by contrast, /S/+nasal clusters are analysed with initial appendices, we expect to find no restrictions on the place of the nasal, parallel to what is observed for $/ \mathrm{S} /+$ stop clusters. This is true: /sm/-/sn/ and /sp/-/st/ are well-formed in English and Dutch, as are $/ \int \mathrm{m} /-/ \int \mathrm{n} /$ and $/ \mathrm{fp} /-$ $/ \int \mathrm{t} /$ in German.

In Section 5.1, we will demonstrate how the last two of these arguments - the lack of place identity effects and of place constraints on the nasal in /SN/ clusters - have important consequences for the child's building of input representations for rising-sonority /S/-initial clusters.

\subsection{Licensing and /S/+rhotic clusters}

In this final subsection on representations, we turn to $/ \mathrm{S} /+$ rhotic clusters. We must motivate the syllabification of $/ \mathrm{Sr} /$ clusters in German, and provide an explanation for their absence from Dutch and English. Recall that /Sr/ is realised as / $\mathrm{r} / \mathrm{in}$ German. Although / $\mathrm{Sr} /$ is illicit in English, $/ \int \mathrm{r} /$ is a well-formed branching onset in this language. We thus end up with two possible analyses for the string $/ / /+/ r /$, as can be seen from a comparison of (11a) and (11b). We will detail the arguments for these two structures below.

(11) Sibilant+rhotic clusters:

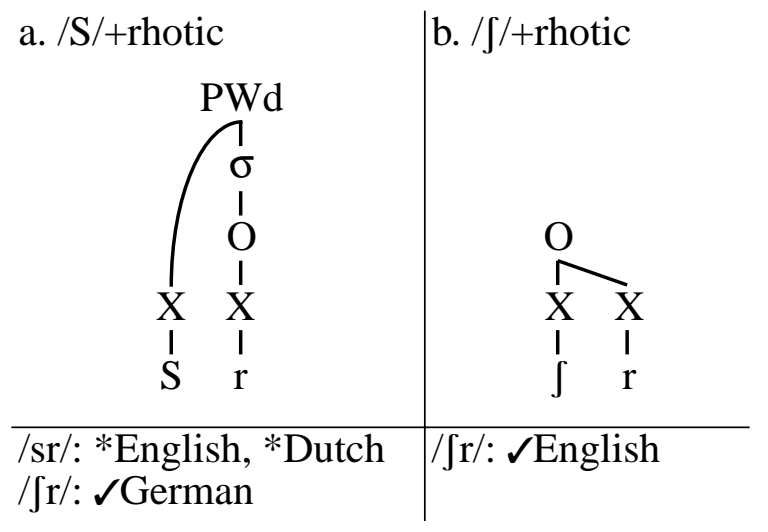

We begin by returning to place identity in branching onsets. In Section 4.1, we proposed that $/ \mathrm{r} /$ is articulatorless which accounts for why it can freely combine with coronals in branching onsets, whereas $/ 1 /$ cannot (English: $/ / \theta \mathrm{r} /, \mathcal{J} / \mathrm{r} / ; * / \theta 1 /, * / \int 1 /$ ). At the same time, however, we mentioned that the well-formedness of $/ \mathrm{S} 1 /$ and $/ \mathrm{Sn} /$ - in spite of place identity - does not necessarily rule out the analysis that these clusters form branching onsets: /S/ could be placeless and these clusters could thereby escape the *PlacEIDENT constraint in (9). This analysis, however, 
offers no explanation for the ill-formedness of $* / \mathrm{Sr} /$ in Dutch and English. If /Sr/ were a branching onset, we would have no explanation for it being illicit in these two languages. /S/, then, must be an appendix, as we have suggested holds for all /S/-initial clusters in the unmarked case.

We are now faced with the task of explaining why the appendix+onset representation is not permitted for / $\mathrm{Sr} /$ in Dutch and English. We propose that the ill-formedness has to do with properties of the head, /r/. In the spirit of Harris (1997: 363-364), we suggest that, in the unmarked case, in order to license a non-head position, a head must have certain strength, where strength is defined in terms of its featural content; specifically, in order to support an appendix or coda, the head of the following onset must bear a Place node.

To exemplify, NC coda+onset clusters which share place are well-formed in most languages, as the onset licenses the place specification (cf. Itô 1986), e.g. [Vm.pV] in (12a) ${ }^{20}$ By contrast, / $/ \mathrm{R}$ in onset position has no articulator to support a preceding coda, and thus, [VN.?V] is most often illicit, even when the coda is itself placeless, (12b). Indeed, when / $/$ / is syllabified as an onset, it is typically restricted to word-initial and intervocalic position. The representation in (12c) demonstrates how this proposal is extended to account for the ill-formedness of $* / \mathrm{Sr} / \mathrm{in}$ English and Dutch. The appendix+onset construction involves a non-head being supported by a placeless head, parallel to the configuration in (12b). Like $/ 2 /, / \mathrm{r} /$ is a well-formed onset when it is wordinitial or intervocalic (and also, a dependent in an onset cluster); as it is articulatorless, however, it cannot license a preceding appendix in the unmarked case.

(12) Licensing of non-head:
a. Coda+strong onset
b. Coda+weak onset
c. Appendix+weak onset
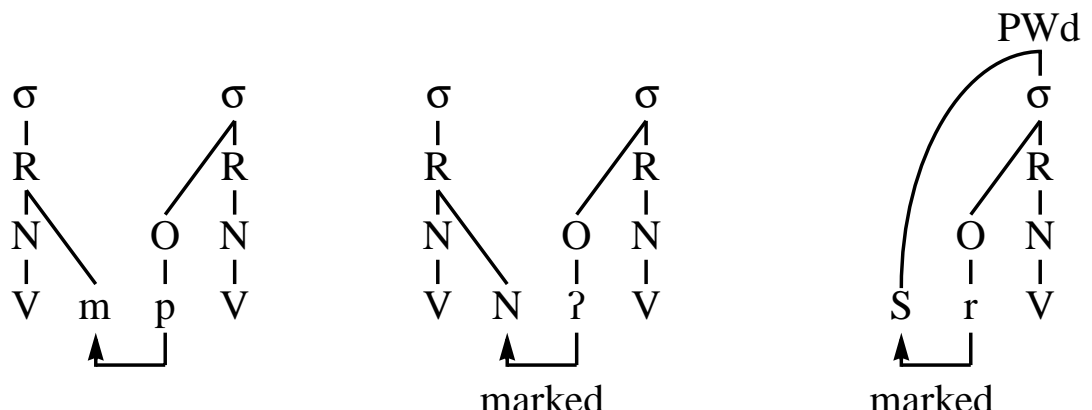

To capture this restriction on appendix licensing, we propose the constraint in (13). This constraint is part of a family of constraints which reflects the melodic restrictions that heads must satisfy in order to support non-heads.

(13) AppendixLicensing(OnsetHead/Place):

An onset head must bear a Place node in order to license an appendix

20. Throughout the rest of the paper, segments abbreviate skeletal positions as well as featural content. 
While (13) is dominant in a number of languages, like Dutch and English, it is violated in German, as indicated in (11a). To be certain of this, however, we must ensure that $/ \mathrm{f} r /$ is truly appendix-initial in German. This sequence could instead have the branching onset structure assigned to English $/ \int \mathrm{r} /$ in (11b). Evidence in favour of the appendix-initial structure comes from the fact that German $/ \int \mathrm{r} /$ displays exactly the same distributional restrictions as do all other appendix-initial clusters in the language; in contrast to branching onsets, it does not occur morpheme-internally (cf. Section 4).

We have arrived at a predicament where both the branching onset and appendix-initial analyses for $/ \mathrm{Sr} /$ are marked. The former is disfavoured on grounds that initial /S/ is optimally syllabified as an appendix. The latter is also disfavoured, as / $\mathrm{r} /$ should ideally not support an appendix. Languages which respect markedness should therefore not tolerate clusters of this shape at all, as is the case in Dutch and English (*/sr/). The German-speaking child, on the other hand, must determine what the appropriate analysis is for the $/ \int \mathrm{r} /$ strings encountered in this language. In Section 6, we will see that Annalena, who follows the head pattern of cluster reduction (cf. (4)), incorrectly treats $/ \int \mathrm{r} /$ as a branching onset: it is $/ \int /$ that survives. More generally, we expect to observe variation across German children who follow the head pattern as concerns their treatment of $/ \int \mathrm{r} /$ clusters.

\subsection{Consequences for acquisition}

In sum, apart from / $\mathrm{r} /$ in German, the representations required for obstruent+liquid and /S/initial clusters in West Germanic correspond to what UG provides as unmarked. ${ }^{21}$ Thus, children should not have too much difficulty building appropriate input representations for such clusters in these languages. It may be the case that cluster reduction prevails for some time, due to highranking structural well-formedness constraints; however, the patterns of cluster reduction should reveal that the appropriate input representations have been assigned, namely that it is the head of the cluster that survives. As we will see, this holds true for children who follow the head pattern of cluster reduction. For those who follow the sonority pattern, however, things are not as straightforward. Recall from Section 2 that, in this pattern, /S/, the non-head, survives in rising sonority /S/-initial clusters. This could indicate that these children have syllabified both members of the cluster in the input, but incorrectly; that is, that they have posited a marked (branching onset) syllabification for /S/+sonorant clusters. We do not accept this view, as indirect negative evidence would be required for the learner to arrive at an analysis where these clusters are syllabified as appendix-initial (cf. Fikkert 1994: 119-120). We proposed earlier that all /S/-initial

21. This is somewhat of a simplification. In contrast to German, recall that English and Dutch are marked in requiring the appendix in /S/-initial clusters to link to the syllable node, rather than to the PWd (see Section 4). Henceforth, we will ignore this difference. 
clusters are appendix-initial in the unmarked case, and if this is indeed true, no indirect negative evidence should ever be required: the first full syllabification analysis entertained by the child should be appendix-initial. If this is so, it must be the case that in the sonority pattern of cluster reduction, inputs are not exhaustively prosodified, that is, that they are impoverished relative to the adult's inputs. This is the position which we adopt, as will be elaborated on in the next section.

\section{Analysis of cluster reduction}

\subsection{Building inputs}

Recall from Section 3 that we consider adult inputs to be fully prosodified. In order for learners to achieve adult-like inputs, they must have some knowledge of the structures that are permitted in the target language, as well as of the relationships that hold across different syllabic projections. For example, syllabification of the branching onset /pl/ in (14a) requires (i) an understanding of headedness, which is assigned to the obstruent (this much comes for free; see below), and (ii) knowledge that complexity is tolerated within the onset constituent, where the liquid constitutes the dependent member of this constituent. ${ }^{22}$ In comparison, understanding of the rising sonority /S/-initial cluster in (14b) requires knowledge (i) that a different headedness relationship is involved (it is the liquid which is assigned as the onset head); consequently, (ii) that there is no branching within the onset constituent, which is universally left-headed (see (7)); and (iii) that the initial /S/ is linked directly to higher prosodic structure (to the PWd, in the unmarked case, as discussed in Section 4). (14c) requires knowledge similar to that involved in the analysis of (14b); however, in all cases other than Dutch /s $\chi /$ which we leave aside, head status is assigned to the least sonorous segment in the string and, thus, comes for free, as in (14a).

(14) Adult inputs:
a. Branching onset
b. Rising sonority /S/-initial
c. Falling sonority /S/-initial
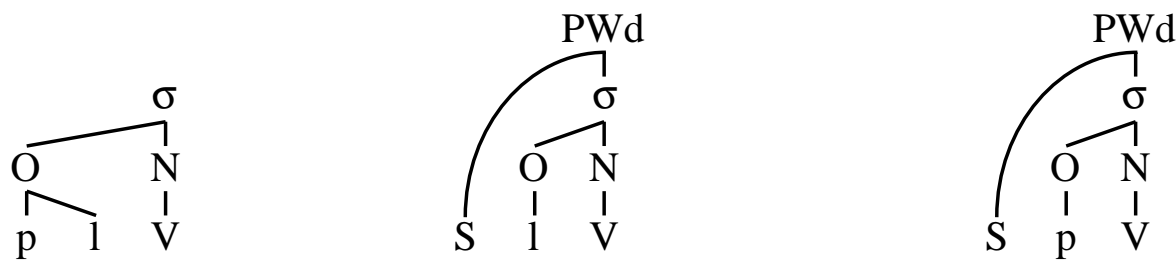

We propose that these elaborate input structures are not mastered at the earliest stage in acquisition. Indeed, they cannot be, as not all languages allow for branching constituents and appendices. Children's inputs are initially prosodified for simplex onsets and rhymes/nuclei only, as in (15). That is, as far as prosodic structure is concerned, inputs only contain CV (core) syllables. Any non-prosodified segmental material that is perceived by the child remains 22. In the interest of space, rhyme nodes have been omitted from all structures. 
unassociated. As all constituents must be headed, the segments syllabified as singleton onsets and nuclei from each of the strings in (15) are by definition the heads of their respective constituents.

What mechanism, though, does the child use to select heads? Without any knowledge of the relations that hold across strings of segments, the head of the onset and the head of the rhyme/nucleus can only be defined on the basis of relative prominence, low sonority (or low airflow) in the former case and high sonority in the latter, in the spirit of Jakobson's (1941/68) Principle of Maximal Contrast. In the strings in (15), which represent the first stage in development (stage 1), the least sonorous consonant will be assigned head status by default. This strategy leads to selection of the correct onset head in (15a) and (15c), as in these cases, there is a correlation between the head of a left-edge cluster and low prominence. However, the incorrect head is selected in rising sonority /S/-initial clusters, (15b).

Inputs for sonority pattern child (stage 1):
a. Branching onset
b. Rising sonority /S/-initial
c. Falling sonority /S/-initial
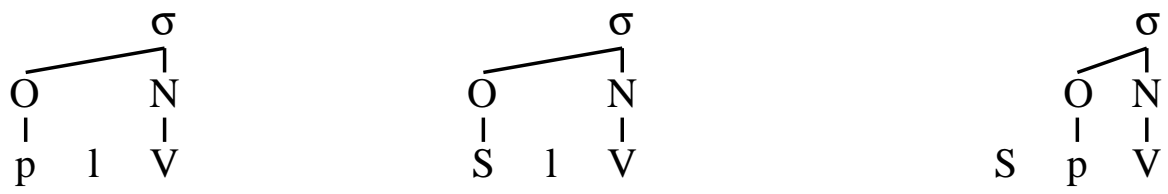

The result is the input specifications for the sonority pattern. Indeed, we propose that the source for the two patterns of cluster reduction is the mismatch between the head of the onset and relative prominence in rising sonority /S/-initial clusters. Correct selection of the head requires an understanding of the distributional (positive) evidence available in the ambient language. The child will be forced to take account of this evidence as s/he attempts to prosodify the remaining segments in the cluster, on the way to achieving adult-like inputs. Accordingly, through the course of acquisition, inputs become more elaborately structured, reflecting this new understanding. The inputs in (16) for the head pattern correspond to this stage in acquisition, which we label stage 2.

(16) Inputs for head pattern child (stage 2):
a. Branching onset
b. Rising sonority /S/-initial
c. Falling sonority /S/-initial
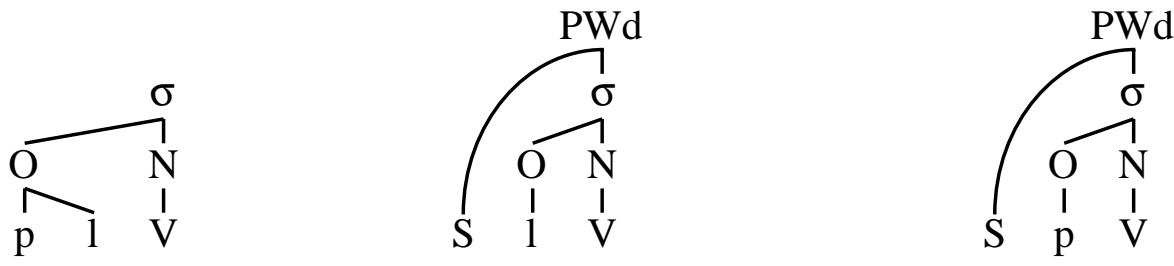
Our analysis of the sonority pattern assumes that there is a stage in development before there is any understanding of syllable-internal complexity beyond the UG-given simplex onsets and rhymes/nuclei. By definition, then, the sonority pattern must precede the head pattern, as is the case for Robin (see Section 2: sonority pattern 1;10.9-2;0.20; head pattern 2;1.9-2;3.24). ${ }^{23}$ However, it need not be the case that all children exhibit both patterns of cluster reduction in their outputs. On the one hand, head pattern children may have come to understand the relations that hold across strings of consonants by the time they attempt to produce words with target clusters, thereby displaying no evidence of having gone through the sonority stage. Prior to this, they may have only selected words for production which do not contain (/S/+sonorant) clusters; this socalled selection and avoidance strategy is common in early acquisition (e.g. Ferguson \& Farwell 1975, Schwartz \& Leonard 1982, Stoel-Gammon \& Cooper 1984). On the other hand, sonority pattern children may skip the head stage of cluster reduction, as their building of target-like input structures may coincide with the demotion of the markedness constraints which had previously prevented the realisation of clusters in their outputs. The latter scenario is perhaps most commonly attested, thereby accounting for the fact that many scholars have remarked on the role that sonority plays in cluster reduction (see Section 1 for references).

For children who exhibit both the sonority and head patterns of cluster reduction, the development from stage 1 to stage 2 will presumably be gradual, unlike what is reflected in the transition from (15) to (16). It is likely that the child will find it easiest to build the target-like input for a branching onset, as (i) the head corresponds to the least sonorous segment and thus is correct from the outset, and (ii) all that is required to prosodify the dependent is to establish an additional link to the onset constituent. However, as long as the markedness constraints which preclude clusters from appearing in outputs are dominant, any stage intermediate between stages 1 and 2 for obstruent-initial and /S/+stop clusters will be impossible to observe in the child's outputs. An empirical difference will only be observable for rising sonority /S/-initial clusters.

Concerning the latter, a common stage intermediate between stages 1 and 2 appears to be that where target-like inputs are built for $/ \mathrm{S} /+$ nasal clusters, but where stage 1 inputs persist for /S/+lateral clusters. With markedness constraints ranked high, this yields the head pattern of cluster reduction for /SN/ clusters, /SN/ $\rightarrow$ /N/, but the sonority pattern for /S1/ clusters, /S1/ $\rightarrow$ /S/. Recall in this context that the Dutch children in Fikkert's study who follow the head pattern (Tom,

23. One of Fikkert's (1994) subjects, Eva, appears to contradict this claim. From Fikkert's Appendix D (p. 326), we observe that Eva's /SN/ clusters initially follow the head pattern, and later, the sonority pattern. Two things make us reluctant to conclude that Eva's data are problematic. One, recall from note 6 that Fikkert remarks that /SN/ clusters are rarely attempted by Dutch-speaking children. We suspect that this is true of Eva, as only one example for each pattern is provided by Fikkert (head pattern: /snœyt/ $\rightarrow$ [nœys] 'snout' $(1 ; 6.1)$; sonority pattern: /snu:pi:/ $\rightarrow$ [zu:pi:] 'Snoopy' (1;9.8)). It is therefore difficult to get a sense of how representative these forms are of Eva's overall profile. Two, the output provided for the sonority pattern surfaces with an initial $[\mathrm{z}]$ which could be due to fusion of $/ \mathrm{s} /$ and $/ \mathrm{n} /$. If this were the case, then [zu:pi:] would be compatible not only with the sonority pattern, but with the head pattern of cluster reduction as well. 
Robin, Catootje) unexpectedly treat /sl/ in the same manner as fricative-initial clusters. This is probably also true of English-speaking Joan (see note 9). ${ }^{24}$ These children thus display reductions as follows: /s/+nasal $\rightarrow$ nasal, but /sl/ $\rightarrow$ /s/ parallel to /fl/ $\rightarrow$ /f/. We believe that these children, in contrast to Amahl and Annalena, are in a stage intermediate between the head and sonority patterns: they have adult-like (stage 2) inputs for /SN/ clusters, but stage 1 inputs for /S1/ clusters. Below, we elaborate on why we consider their /S1/ clusters to behave unexpectedly from the point of view of the head pattern.

As discussed in Section 4.2, both /Sl/ and /SN/ are ill-formed as branching onsets, and some children, those who follow the head pattern in its entirety, clearly attend to the various types of evidence available for this at once. Other children, those who fall into the intermediate pattern, seem to have latched onto the fact that there are significant differences between laterals and nasals as concerns their distribution in clusters. On the one hand, the lack of place constraints on the nasal in /SN/ clusters provides clear evidence for the child to come to an early understanding of clusters of this shape. Specifically, in spite of the rising sonority, labial place on $/ \mathrm{m} /$ signals that /Sm/ could never be a branching onset. Thus, once the child attempts to incorporate the nasal into his/her stage 1 input syllabification, labial place forces a reanalysis of this segment as head. This results in the appendix-initial input representation at stage 2 for $/ \mathrm{Sm} /$ and, by extension, for $/ \mathrm{Sn} /$ as well.

Building adult-like input representations for /S1/ clusters, on the other hand, is less straightforward, because $/ 1 /$, unlike $/ \mathrm{m} /$, is an optimal onset dependent. Thus, when the child attempts to incorporate /// into his/her stage 1 input forms, s/he may first try to syllabify /S1/ as a branching onset. The place identity facts, however, are not consistent with this analysis. There is thus a conflict as concerns the syllabification of /1/ that may delay some children's incorporation of this segment into their input syllabification, resulting in the maintenance of the impoverished stage 1 structure for /S1/ for some time after /SN/ clusters have been appropriately prosodified (as per stage 2). This, in essence, is a type of selection and avoidance. What, though, ultimately compels these children to move beyond their stage 1 forms and to posit the appropriate input representation for $/ \mathrm{S} 1 /$ ? We suggest that it must take place on grounds of parsimony, that is, to resolve the fact that $/ \mathrm{Sl} /$ is an outlier as concerns the full prosodification of inputs.

Henceforth, we will ignore the different treatment of /Sl/ and /SN/, and will consider the learners as falling into two groups only, as we had earlier: head pattern children and sonority pattern children, where those children who fall into the intermediate stage are grouped with those who follow the head pattern in its entirety.

In the following two sections, we turn to the constraints required to capture cluster reduction. We then demonstrate in Section 5.4 that, in comparing the sonority and head pattern

24. Joe Pater (personal communication) informed us that this holds of English-speaking Trevor as well. 
children, even though their input representations differ in terms of how elaborately structured they are, the same set of markedness constraints yields only CV syllables on the surface for both groups. In comparing the head pattern children with adults, we maintain that, although these children have target-like inputs, their grammar differs from the end-state grammar in terms of the relative ranking of markedness constraints and segmental faithfulness.

\subsection{Constraints}

To reflect the structural differences that are observed between branching onsets and appendix-initial clusters, two markedness constraints are required, those in (17).

(17) Markedness constraints:

a. ${ }^{*} \operatorname{COMPLEX}(\alpha)$

Sub-syllabic constituents cannot branch $\alpha \in\{$ Onset, Rhyme, Nucleus $\}$

b. *APPENDIX-LEFT/(RigHT)

A consonant at the left/(right) edge must be immediately dominated by Onset/(Rhyme)

*Complex, initially proposed by Prince \& Smolensky (ms), rules out branching within a constituent. We assume, as do others, that *COMPLEX is a family of constraints that takes syllable-internal constituents as its arguments. We limit these constituents to onset, rhyme and nucleus. $^{25}$ Since our focus is on left-edge clusters, we are only concerned with *COMPlex(ONSET), but we will use the label *COMPLEX for convenience. *APPENDIX-LEFT/ (RIGHT) requires a consonant to be directly dominated by the constituent that would normally organize it: by the onset at the left edge, and by the rhyme at the right edge (see Sherer 1994 for a different formulation of this constraint). *APP-LEFT is violated when a segment is linked directly to the PWd (or syllable node), as in the case of /S/ in left-edge clusters.

For children who follow either the sonority or head pattern of cluster reduction, *COMPLEX and *APP-LEFT must both be undominated. These two constraints cannot be collapsed. First, we observed in (6) that the presence or absence of branching onsets is independent of the presence or absence of appendix+onset clusters: in Spanish (6a), *APP-LEFT must be undominated while *COMPLEX is lowly ranked; in Acoma (6b), *COMPLEX is undominated and *APP-LEFT lowly ranked. Second, in the acquisition literature on West Germanic, it has often been observed that

25. As was evident from our structures in (12a,b), we do not accept the coda as a formal constituent (see esp. Kaye 1990); coda consonants are instead linked directly to the rhyme. This is in part because we do not accept the existence of branching codas, as would be expected if the coda were a licit argument of *COMPLEX. Instead, we adopt the view that final clusters which fall in sonority are heterosyllabic, with the second consonant syllabified as the onset of an empty-headed syllable (on the latter, see e.g. Giegerich 1985, Kaye 1990, Piggott 1991, Rice 1992, Zonneveld 1993, Harris 1994; see Goad \& Brannen to appear on L1). 
branching onsets and appendix+onset clusters do not emerge at the same point in development (e.g. Smith 1973, Fikkert 1994, Barlow 1997, 1999).

Satisfaction of the constraints in (17) comes at the expense of violating segmental faithfulness. Faithfulness constraints favour a good match between any two pairs of strings that stand in a dependency or correspondence relation. Correspondence is defined in (18) (from McCarthy \& Prince 1995: 262). For our purposes, $S_{1}$ is the input, and $S_{2}$, the output.

(18) Correspondence:

Given two strings $S_{1}$ and $S_{2}$, correspondence is a relation $\Re$ from the elements of $S_{1}$ to those of $S_{2}$. Elements $\alpha \in S_{1}$ and $\beta \in S_{2}$ are referred to as correspondents of one another when $\alpha \Re \beta$.

As children rarely epenthesise into consonant clusters, we will only be concerned with the faithfulness constraint that forbids deletion, MAX-IO, as defined in (19). This constraint must be lowly ranked in children's early grammars, as satisfaction of *COMPLEX and *APP-LEFT comes at the expense of segmental deletion.

(19) Segmental faithfulness:

MAX-IO: Every segment of the input has a correspondent in the output

A second faithfulness constraint is required, MAXHEAD-IO, as defined in (20). This constraint ensures that segments prosodified in the head of a constituent are preserved as such in the output. While MAXHEAD is technically a faithfulness constraint, it has a markedness element to it as well, as it makes reference to heads which, we have already mentioned, have a primacy not accorded to non-heads.

(20) Head faithfulness:

MAXHEAD(PCAT)-IO: Every segment prosodified in the head of some prosodic category in the input has a correspondent in the head of that prosodic category in the output

PCat $\in$ \{Onset, Nucleus, Rhyme, $\sigma$, Foot... $\}$

A number of questions emerge from the formulation of this constraint, concerning the arguments that it takes, the way that headedness is expressed in inputs, and the role that this constraint plays outside of child language. We will address each of these in turn in the next section.

\subsection{More on MAXHEAD}

Constraints that express faithfulness to prosodic heads have been proposed throughout the OT literature, in particular, those that express faithfulness to heads of feet (see e.g. Alderete 1995, Pater 2000, Itô et al ms, McCarthy ms). ${ }^{26}$ In the spirit of Alderete (1995), we have proposed a 
generalised head faithfulness constraint, one that takes a number of prosodic categories as arguments. As we assume that the sub-syllabic constituents of the syllable are onset, rhyme and nucleus, these constituents fall into the class of categories that can be exploited by (20). The category that may appear suspect is onset. We will see in Section 5.4 that MAXHEAD(ONSET) plays a crucial role in our analysis of L1 cluster reduction. A question that immediately arises is whether there is any evidence for MAXHEAD(ONSET) outside of acquisition. We will briefly demonstrate below that it plays a role in the distribution of branching onsets in a dialect of Brazilian Portuguese. More generally, the analysis of Brazilian Portuguese provides empirical support in favour of the position that adult inputs must be fully prosodified, thereby confirming the need for a generalised head faithfulness constraint like (20).

In southeastern Brazilian Portuguese, branching onsets are only tolerated in stressed syllables. Input clusters are otherwise reduced, as can be seen from the data in (21) (from Harris 1997: 363).

(21) Branching onsets in southeastern Brazilian Portuguese:
a. prátu 'plate'

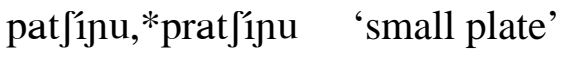
b. lívu, *livru 'book'
livrétu 'small book'

Harris (1997) points out that branching onsets are restricted to prosodically strong positions in other languages as well. For instance, in German hypocoristics, such structures are not permitted

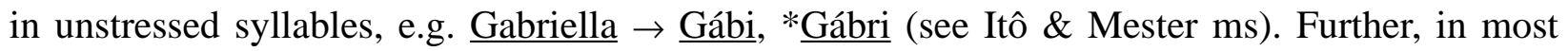
languages, branching onsets are not tolerated before phonetically empty nuclei (with the notable exception of continental French, e.g. sablØ 'sand' (Charette 1991)); most dialects of Québec French are like this and alternations are observed in this context, e.g. $\underline{\text { sab } \emptyset}$, *sablØ 'sand' vs. sabl-e 'to sand' (see Nikièma 1999 for a recent structurally-based account). Finally, Y. Rose (2000) has shown that the Brazilian Portuguese pattern is found in the L1 acquisition of Québec French. Importantly, in all of these cases, it is the head of the onset which survives cluster reduction.

Let us turn now to demonstrate how MAXHEAD interacts with *COMPLEX to arrive at the pattern observed in Brazilian Portuguese. The tableau in (22) reveals that two MAXHEAD constraints are required, MAXHEAD(FoOt) and MAXHEAD(Ons), both of which must be ranked above *COMPLEX. (Parentheses mark the edges of feet, and periods, the edges of syllables.)

26. These proposals, including the one in (20), make different empirical claims which will not be addressed here. The reader is referred to the original sources for further details. 
(22) Southeastern Brazilian Portuguese:

\begin{tabular}{|c|c|c|c|c|c|c|}
\hline & & & MAXHD(FT) & MAXHd(Ons) & *COMPLEX & MAX \\
\hline \multirow[t]{2}{*}{ a. li(vré.tu) } & 膤 $\mathrm{i}$ & i. li(vré.tu) & & & * & \\
\hline & & ii. li(vé.tu) & $* !$ & & & * \\
\hline \multirow[t]{3}{*}{ b. (lí.vru) } & & i. (lí.vru) & & & $* !$ & \\
\hline & 吗 $\mathrm{i}$ & ii. (lí.vu) & & & & * \\
\hline & & iii. (lí.ru) & & $* !$ & & * \\
\hline
\end{tabular}

Dominant MaxHeAd(FT) ensures that all segments contained in the head of the foot, [vré], will be realised on the surface. Thus, in (22a), the optimal candidate is (i), in spite of the violation incurred for *COMPLEX. In (22b), the input branching onset is not located in head position. Thus, $\operatorname{MAXHEAD}(\mathrm{FT})$ is not relevant, and the cluster is reduced to satisfy *COMPLEX, as in candidates (ii) and (iii). MAXHEAD(ONS) factors into the selection between these two candidates. The former is selected as optimal, as the consonant that survives, [v], is the head of the onset cluster in the input.

Importantly, all segments prosodified within the head of the foot, the syllable underlined in li(vré.tu), must surface in order to completely satisfy $\operatorname{MaxHEAD}(\mathrm{FT})$, as defined in (20). This requires that inputs be fully prosodified. If only syllable peaks were prosodified in inputs, $\operatorname{MAxHEAD}(\mathrm{FT})$ could not select between (22a.i) and (22a.ii), as the vowel from the input stressed syllable is present in both candidate outputs.

A consequence of full syllabification is that heads of constituents must be structurally defined, rather than based on relative prominence. This is particularly important as concerns onsets; although in the case of feet, the head syllable is the most salient, recall from earlier discussion that in left-edge clusters, there is no correlation between relative prominence and headedness. This, in fact, is central to our explanation of the two patterns of cluster reduction observed in early grammars.

\subsection{Tableaux}

In the following sections, we illustrate how highly-ranked MAXHEAD(ONS) yields the desired outputs for both the head and sonority patterns of cluster reduction. Recall from earlier discussion that the difference between these patterns can only be observed in /S/+sonorant clusters. In input branching onsets and /S/+obstruent clusters, the distinction is obscured by the fact that the head of the cluster is also the segment that has the lowest sonority. In this section, we will exemplify how the constraints presented in Section 5.2, in combination with the input representations proposed in Section 5.1, yield the correct results for the patterns observed. We will focus on branching onsets and on rising sonority /S/-initial clusters only. 


\subsubsection{Branching onsets}

For children who follow either pattern of cluster reduction, the ranking of constraints is the same: the markedness constraints *COMPLEX and *APP-LEFT dominate, thereby ensuring that no clusters are realised on the surface, at the expense of violating MAX. The highly-ranked MAXHEAD will determine which consonant from the input survives. (As our focus is now on onsets, we abbreviate MAXHEAD(Ons) as MAXHEAD for convenience.)

As discussed earlier, children who follow the sonority pattern equate headedness with low sonority. Headedness is thus correctly assigned to the stop in (23), in spite of the fact that input obstruent+liquid clusters contain no knowledge of branching structure.

(23) Stage 1: sonority pattern:

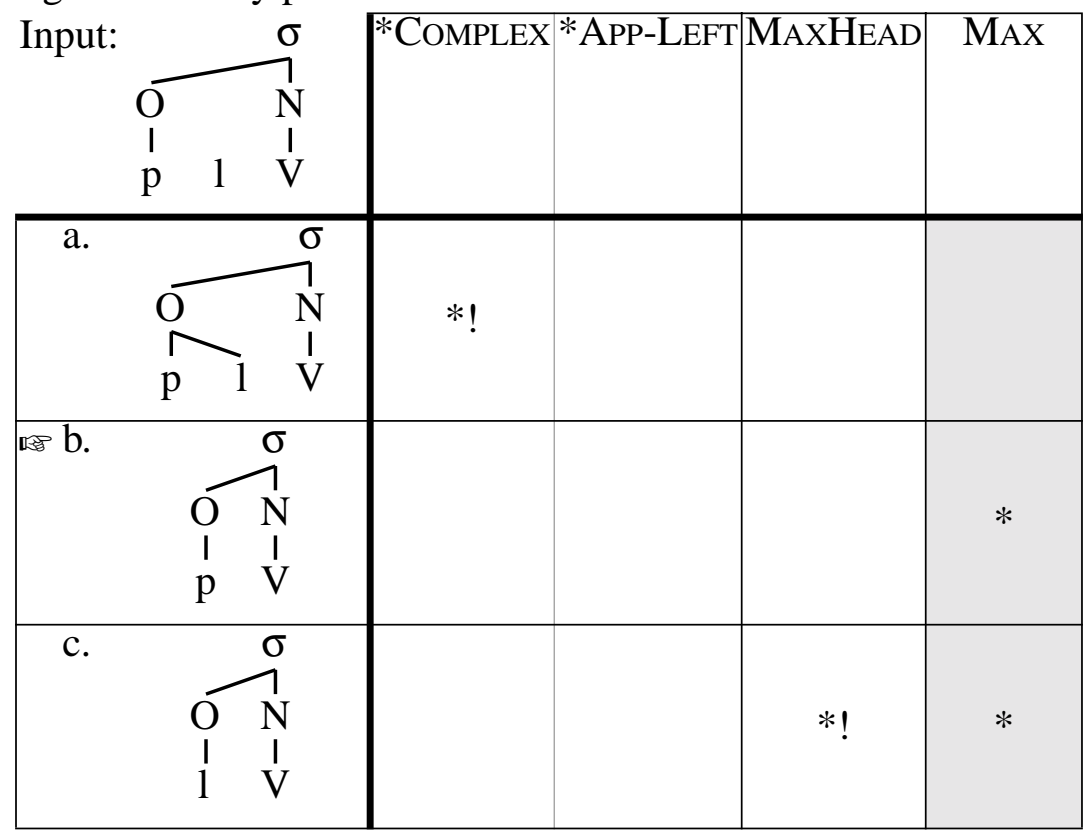

For children who follow the head pattern, by contrast, inputs are adult-like and headedness is thus structurally determined, as can be seen from the input in (24). 
Goad \& Rose - 29

(24) Stage 2: head pattern:

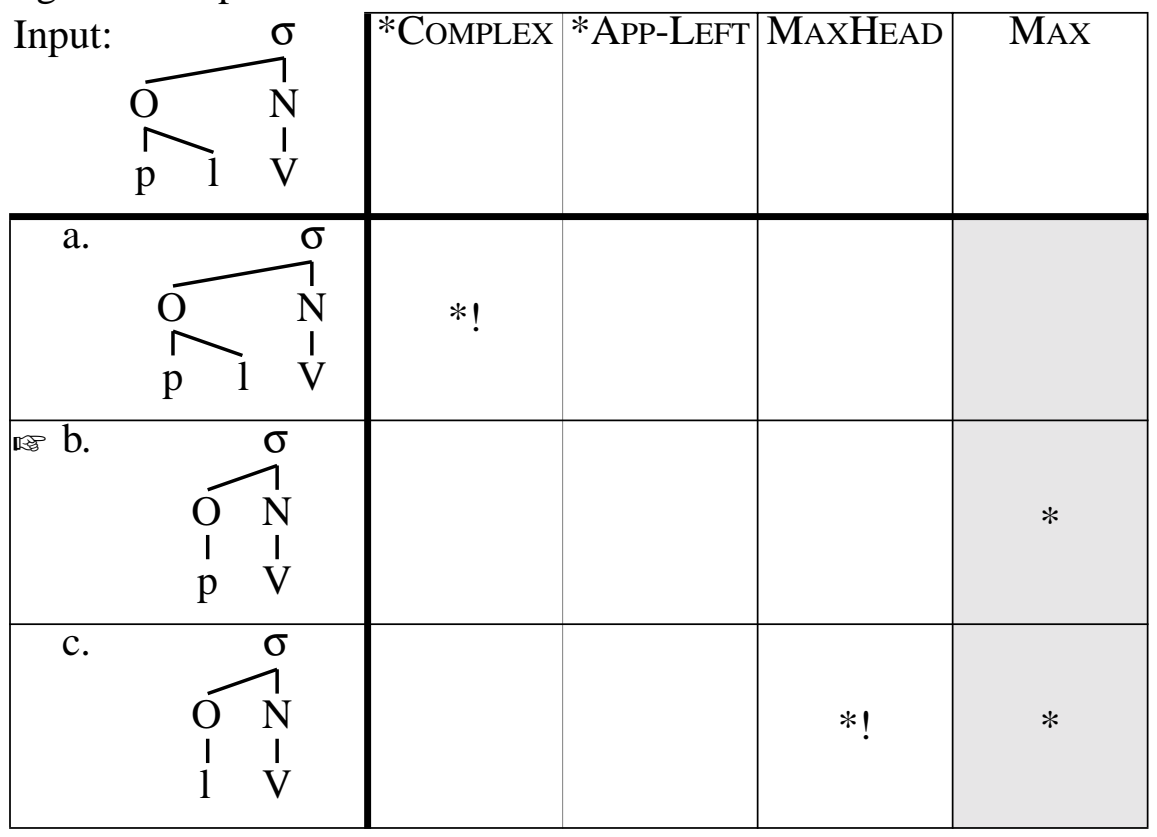

In the list of candidates in (23) and (24), those which preserve the input cluster, (23a) and (24a), fail on the markedness constraint ${ }^{*}$ COMPLEX. ${ }^{27}$ The decision between the remaining two candidates rests with MAXHEAD. While the inputs for children who follow the sonority versus head patterns differ, in both cases, the head of the cluster is the obstruent. Thus, MAXHEAD selects candidate (b) in both (23) and (24). In candidate (c), the input head has been deleted in favour of the liquid.

In the interest of space, we will not provide a tableau for the adult grammar. As mentioned earlier, the adult inputs are the same as those for the head pattern child. The two grammars differ in terms of their ranking. In the adult grammar, the faithfulness constraints dominate the markedness constraints under discussion with the result that the candidate with the branching onset, (24a), is selected as optimal.

\subsection{2 /S/+sonorant clusters}

While the same output is selected for both head and sonority pattern children in obstruent+liquid and /S/+obstruent clusters, this is not the case in /S/+sonorant clusters, as the structurally-determined head does not correspond to the segment that is least sonorous. Although the correct head in clusters of this shape is the second consonant, children who abide by the sonority pattern wrongly assign head status to /S/, as depicted in the input representation in (25).

27. We have not provided candidates where $[\mathrm{p}]$ is syllabified as an initial appendix. Such candidates will violate *APPLEFT, MAXHEAD, and other constraints which assess the segmental content of left-edge appendices. 
Goad \& Rose - 30

(25) Stage 1: sonority pattern:

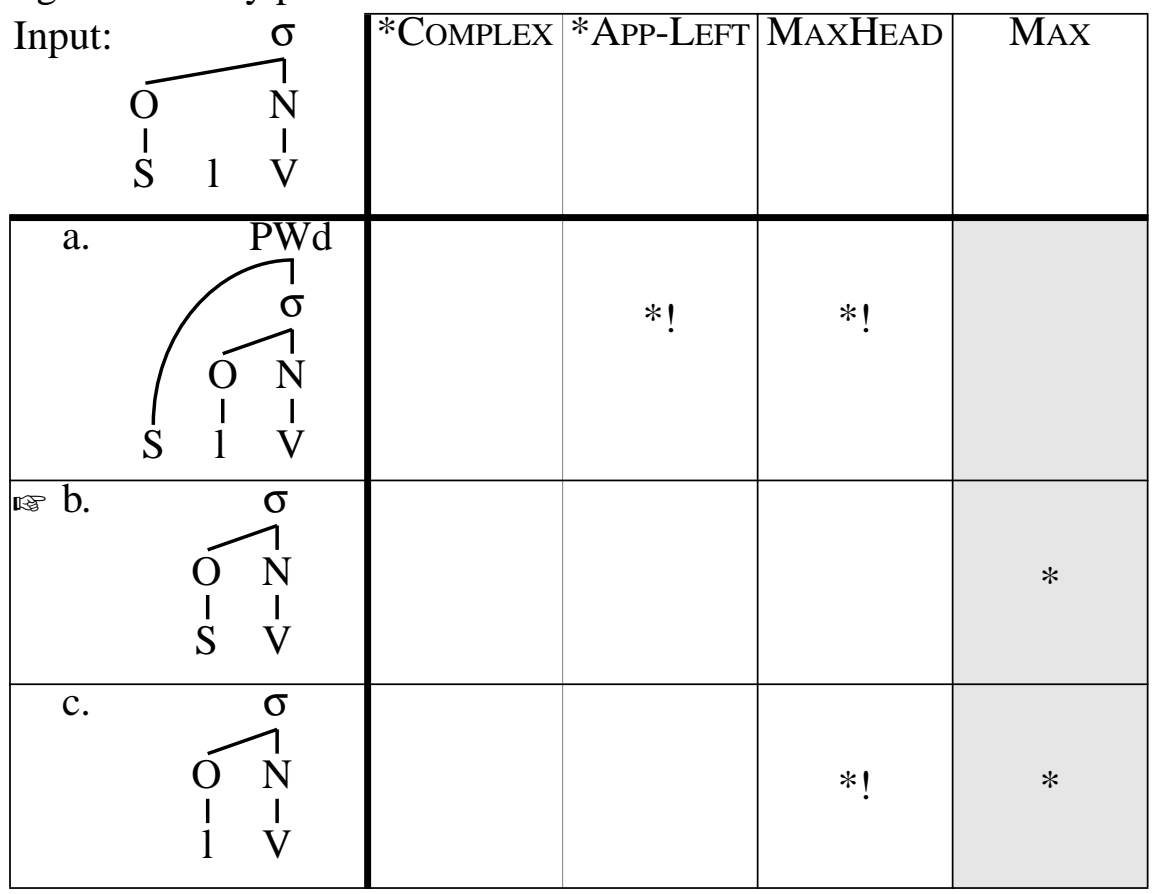

The input structure in (26), by contrast, reveals that children who follow the head pattern have correctly assigned head status to the sonorant, on the basis of the patterns of distribution to which they have been exposed. It is this difference in headship in inputs that yields the two patterns of cluster reduction observed on the surface.

The first candidate in each of (25) and (26) violates the undominated *APP-LEFT. ${ }^{28}$ Interestingly, (25a), which is the correct adult output, also violates MAXHEAD. This would not be the case in the adult grammar, as inputs for clusters of this shape have head status assigned to the liquid. (25b) and (25c) are the remaining contenders for the sonority pattern. As the latter fatally violates MAXHEAD, the form with liquid deletion is selected as optimal. The same reasoning applies to the remaining two candidates for the head pattern in (26), with one crucial difference: children who follow this pattern correctly assign head status to the sonorant. Thus, MAXHEAD preserves this segment over/S/, as in (26c).

28. The branching onset candidate has not been provided for input /S1/. This candidate will violate a constraint such as $\mathrm{S}=\mathrm{APP}$ which requires that /S/ be optimally syllabified as an appendix. In the case of left-edge clusters, $\mathrm{S}=\mathrm{APP}$ will interact with other constraints on syllabification, in particular ONSET, to ensure that /S/ is only syllabified as an appendix when followed by another consonant. 
Goad \& Rose - 31

(26) Stage 2: head pattern:

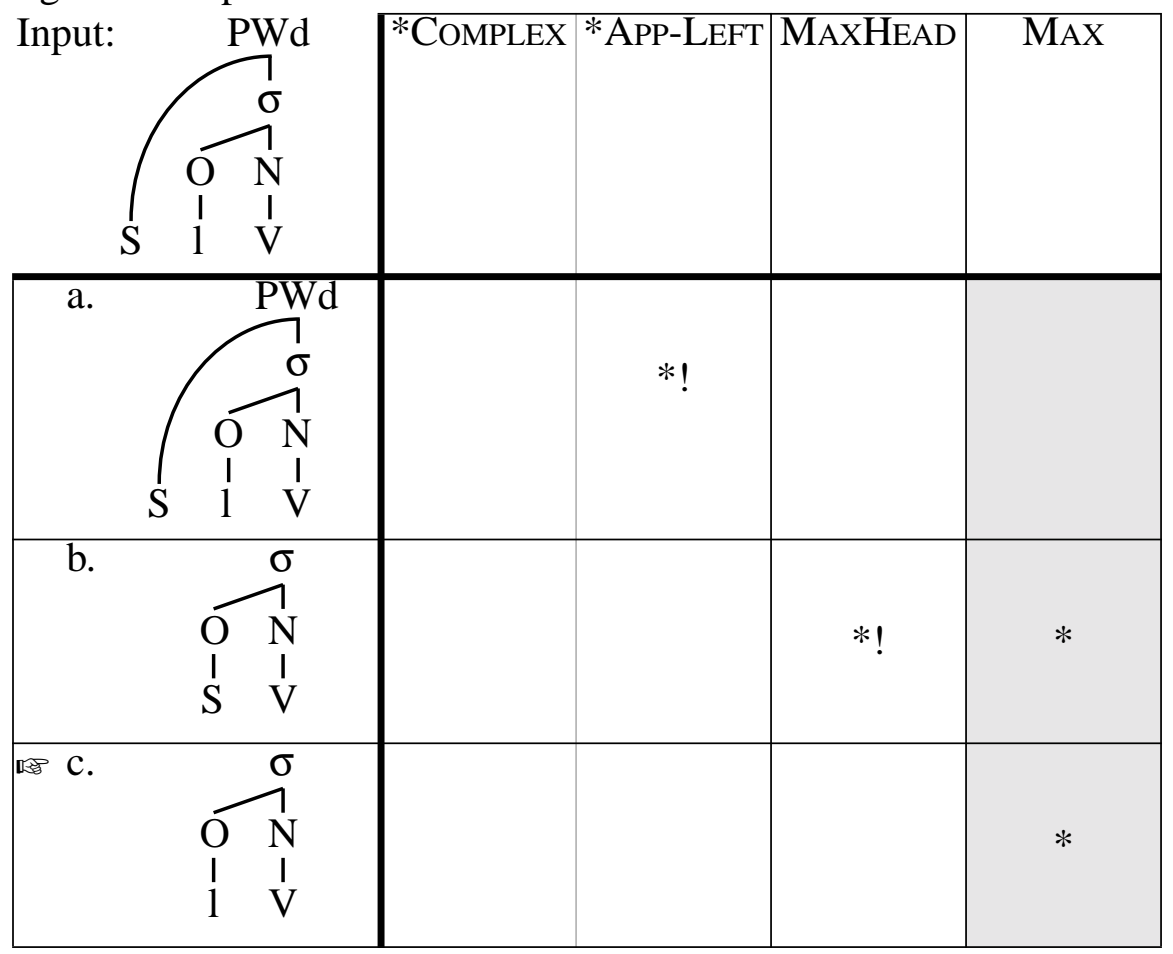

In the adult grammar, inputs are identical to those posited by children who follow the head pattern, as discussed earlier. Since both faithfulness constraints dominate *APP-LEFT, (26a) would be selected as optimal.

Our analysis of the head and sonority patterns has appealed to highly-articulated representations as well as to constraints that directly reference these representations. It has not relied on a difference in constraint ranking across the two stages. While our account of the sonority pattern, stage 1 , was built on the relationship between sonority and headedness, this was only true as concerns the elaboration of inputs. We did not invoke a family of sonority-based constraints for the selection of outputs, because these constraints appear to play no role in the head pattern. In the next section, we briefly consider an alternative analysis, one where the differences observed between the two patterns of cluster reduction arise because of differences in ranking between sonority-based constraints and MAXHEAD. We will argue that such an analysis must be rejected.

\subsection{Is constraint re-ranking an alternative?}

We have put the burden of explanation for the two patterns of cluster reduction on the elaboration of inputs, rather than on constraint re-ranking. Under our approach, both groups of children preserve constituent heads in their outputs. The difference between the two groups rests 
with children's (mis)understanding of what constitutes the head in a given cluster type. An approach which instead relies on constraint ranking would entail that, at stage 1, sonority pattern children have constituent heads correctly assigned, but that they are not faithful to heads when considerations of sonority take precedence, that is, in rising sonority /S/-initial clusters. Let us call this ranking LOWSONORITY >> MAXHEAD for convenience (cf. Section 7.2 where LOWSONORITY is spelled out as Prince \& Smolensky's (ms) *M(ARGIN)/ $\lambda$ ). At stage 2, head preservation would become more central, reflected in a grammar where sonority-based constraints rank below MAXHEAD (ranking MAXHEAD >> LOWSONORITY). We reject this approach for three reasons.

First, while the ranking at stage 1 is consistent with what most scholars accept to be the initial ranking provided by UG, Markedness >> Faithfulness (e.g. Demuth 1995, Smolensky 1996, Gnanadesikan this volume), there is no evidence in the language to which children are exposed that would lead to the new ranking at stage 2: while heads are faithfully produced in adult outputs, so are non-heads. Thus, there is no evidence to trigger, and nothing to be gained by, the re-ranking observed at stage 2 . The only positive evidence that will lead to a re-ranking is the fact that clusters are tolerated, demonstrating that the relevant markedness constraints must be dominated in the target grammar.

Second, at this early stage in our investigation, we regard as somewhat dubious any explanation of cluster reduction that does not rely on faithfulness to heads, given that all linguistic constituents are headed, that heads have a primacy not accorded to non-heads, and following from this, that non-heads are dependent for their very existence on the presence of a head (see earlier Section 4).

Finally, as far as we have observed, the only widely attested pattern of cluster reduction that appears not to rely on head preservation is the sonority pattern. ${ }^{29}$ Other possible patterns seem to be rare at best, for instance the contiguity pattern where the consonant which survives is the one contiguous with the input vowel: obstruent+sonorant $\rightarrow$ sonorant, /S/+stop $\rightarrow$ stop, /S/+sonorant $\rightarrow$ sonorant. Indeed, our investigations have turned up only two children whose grammars follow this pattern (see also Bernhardt \& Stemberger 1998: 388-389). One is Subject 12, a languagedelayed learner of English (from Chin \& Dinnsen 1992); the other is María, a normallydeveloping learner of Spanish (Lleó \& Prinz 1996). ${ }^{30}$ The rarity of children whose cluster reduction patterns respect contiguity is consistent with the analysis provided earlier in Section 5.

29. Here, we are concerned with children whose reduction patterns can be described by reference to prosodic structure, linear position, or sonority. Beyond sonority, we do not consider patterns which may be defined on the basis of the featural content of the segments involved. For the latter, we draw the reader's attention to Jongstra (ms).

30. Of the four Spanish learners investigated by Lleó \& Prinz, one other child, Juan, produced a relatively high number of outputs consistent with the contiguity pattern, 54\% (cf. María's 84\%). Note that the percentages provided by the authors collapse $\mathrm{C}+$ liquid and $\mathrm{C}+$ glide clusters (even though glides are syllabified in the nucleus in the adult grammar. Finally, recall from (6a) that Spanish does not tolerate $/ \mathrm{s} /+\mathrm{C}$ clusters at the left edge and, thus, the data include obstruent-initial targets only. 
As we proposed a head-based analysis of the sonority pattern, we reiterate our point that heads have a primacy not granted to non-heads.

Before concluding our discussion of cluster reduction, one pattern remains to be analysed: Annalena's treatment of /S/+rhotic clusters. We turn to this topic next.

$6 / \mathrm{S} /+$ rhotic clusters in the head pattern: Annalena's grammar

The analysis that we have provided for rising sonority /S/-initial clusters in the head pattern cannot account for Annalena's treatment of $/ \int \mathrm{r} /$ clusters in German. Recall from (4) that while in $/ \int /+$ lateral,nasal,glide clusters, it is the sonorant that survives cluster reduction, in $/ \int /+$ rhotic clusters, it is / $\int /$ that survives. The table in (27) reflects the analysis: although Annalena has the correct appendix-initial structure for $/ \int 1 /, / \int \mathrm{N} /$, and $/ \int \mathrm{v} /$, she has assigned branching onset status to $/ \int \mathrm{r} /$.

Analyses for / $/$ /+sonorant clusters:

\begin{tabular}{|c|c|c|}
\cline { 2 - 3 } \multicolumn{1}{c|}{} & Target German & Annalena \\
\hline a. $/ \int \mathrm{l} /$ & Appendix-initial & Appendix-initial \\
$/ \int \mathrm{N} /$ & Appendix-initial & Appendix-initial \\
$/ \int \mathrm{v} /$ & Appendix-initial & Appendix-initial \\
\hline b. $/ \int \mathrm{r} /$ & Appendix-initial & Branching onset \\
\hline
\end{tabular}

Beyond the reduction patterns, additional support for the branching onset analysis of Annalena's $/ \int \mathrm{r} /$ comes from examining the point at which she acquires the various cluster types. The table in (28) reveals that $/ \int \mathrm{r} /$ clusters emerge as target-like at the same point as do obstruent+/r/ (Cr) clusters. The remaining / //-initial clusters (/ //+stop, / //+nasal, / $\left.\mathrm{l} 1 /, / \int \mathrm{v} /\right)$ are not acquired until much later. 31

(28) Annalena's order of acquisition:

\begin{tabular}{|c|c|c|c|}
\hline $\mathrm{Cl}$ & $\mathrm{Cr}$ & $\int \mathrm{r}$ & $\int \mathrm{C}($ except $\mathrm{r})$ \\
\hline $1 ; 11.15-2.0$ & $1 ; 09-1 ; 10$ & $1 ; 09-1 ; 10$ & $2 ; 02.15-2 ; 04$ \\
\hline
\end{tabular}

In Section 4.3, we attributed the markedness of the appendix-initial structure for $/ \mathrm{f} /$ to properties of the head. Specifically, we proposed that an onset head must bear a Place node in order to license an appendix, AppLic(OnsHd/PL) in (13). While (13) is undominated in English and Dutch, it is violated in adult German, as indicated earlier in (11a) and again in (27b). We can

31. Concerning Annalena's relatively late acquisition of obstruent+/l/ $(\mathrm{Cl})$ clusters, it is worth pointing out that van der Torre (2001) has provided cross-linguistic evidence in favour of obstruent+/l/ branching onsets as more marked than obstruent+/r/. Prior to $1 ; 11.15$, Annalena goes through a brief period of metathesis, ClV $\rightarrow$ CV1. Concerning 2;02.15 as the point of acquisition of $\int \mathrm{C}$, there are a few cases of target-like productions of these clusters before this time, starting at about 1;11; however, systematic productions are not attested until 2;02.15. 
appeal to the marked status of the appendix-initial structure for $/ \int \mathrm{r} /$ to explain why Annalena does not analyse this cluster in this fashion. However, this will not explain why she treats $/ \mathrm{fr} / \mathrm{as}$ a branching onset, as the branching onset analysis of this cluster is also marked (see Section 4.3 and note 28).

The fact that both parses for German $/ \mathrm{f} r /$ are marked may have led us to expect that Annalena would avoid clusters of this shape altogether, as do adult English and Dutch (*/sr/). This, however, is not the case (although it is for German-speaking Naomi (Janet Grijzenhout personal communication)). As to why Annalena opts for the branching onset analysis over the appendix-initial analysis, we cannot be sure. Nevertheless, we speculate that it is tied to the fact that German /S/ appears as / // and not as /s/. Recall from (11) that in English, where /S/ appears as /s/, / $\mathrm{r} /$ clusters are tolerated as branching onsets. Given that UG permits two analyses for the string $/ \int \mathrm{r} /$, it is possible that Annalena has analysed the $/ \mathrm{J} /$ of German $/ \int \mathrm{r} /$ like English $/ \mathrm{J} /$, and thus differently from the $/ \mathrm{J} /$ of other $/ \mathrm{S} /$-initial clusters in the language. In the absence of evidence to the contrary, we will assume that this analysis is correct.

The tableaux in (29) and (30) contrast Annalena's treatment of $/ \int \mathrm{r} /$ and $/ \int 1 /$ respectively. As compared to the tableaux provided earlier in (23)-(26), we have added the constraint AppLic(OnsHd/PL) which is directly relevant to the assessment of /Sr/ clusters. In the case of the input branching onset in (29), the faithful candidate, (a), violates *COMPLEX. Candidate (b) violates a number of markedness constraints, notably ApPLic(OnsHd/PL), because the head of the cluster, /r/, cannot support an appendix. In adult German, this constraint must be lowly ranked to permit $/ \int \mathrm{r} /$ to be well-formed as an appendix-initial cluster. Among the two remaining candidates, (c) is selected as optimal in Annalena's grammar, as it does not incur a violation of MAXHEAD. 
Goad \& Rose - 35

(29) Annalena's grammar for $/ \int \mathrm{r} /$ :

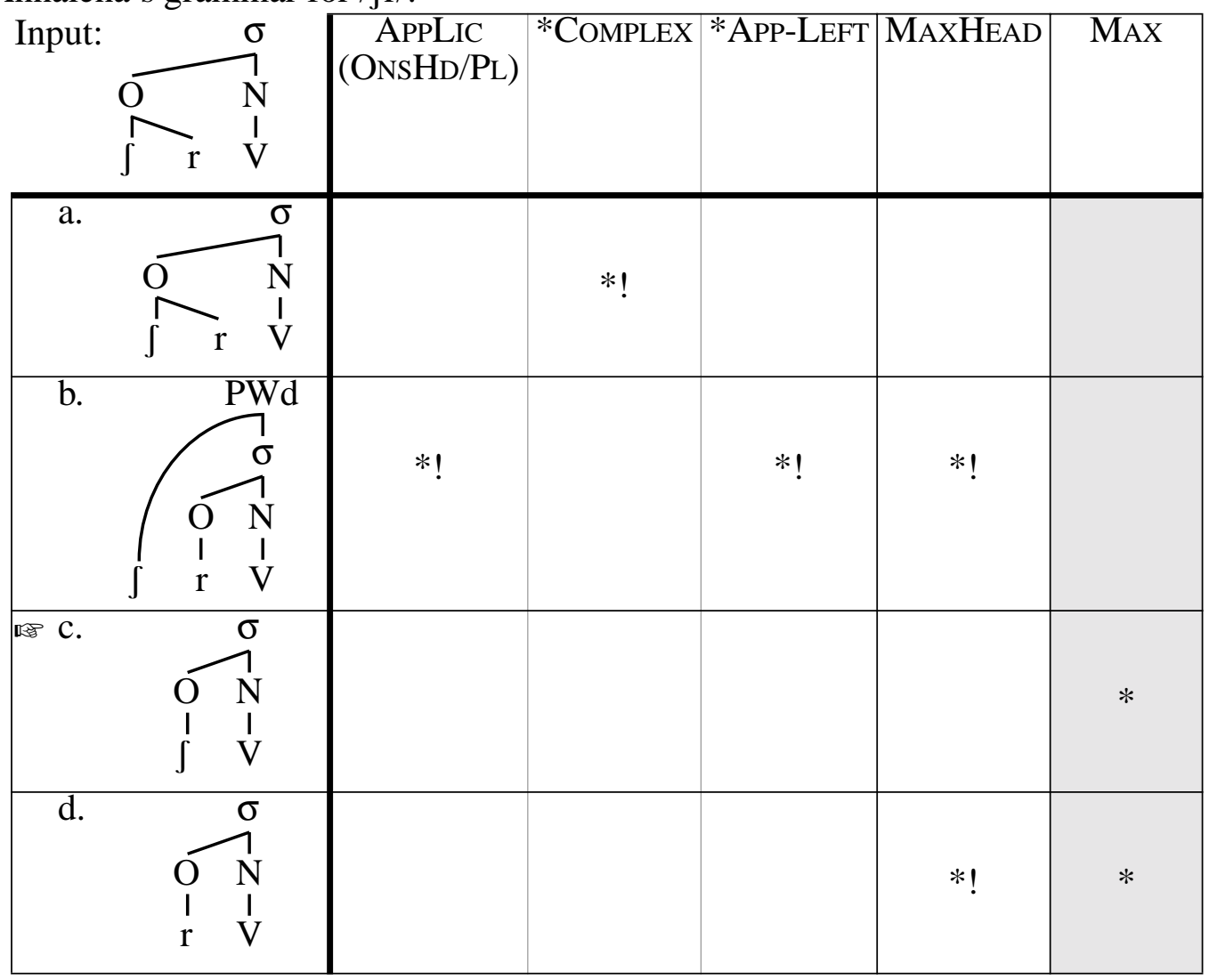

Turning to (30), in this case, Annalena has the correct adult input. AppLic(OnsHd/PL) is not violated by candidate (a) because the head of the cluster, /1/, bears a Place node (cf. (10a)). Nevertheless, dominant *APP-LEFT prevents this form from surfacing in favour of candidate (d), the only other form where MAXHEAD is respected. 
(30) Annalena's grammar for $/ \int 1 /$ :

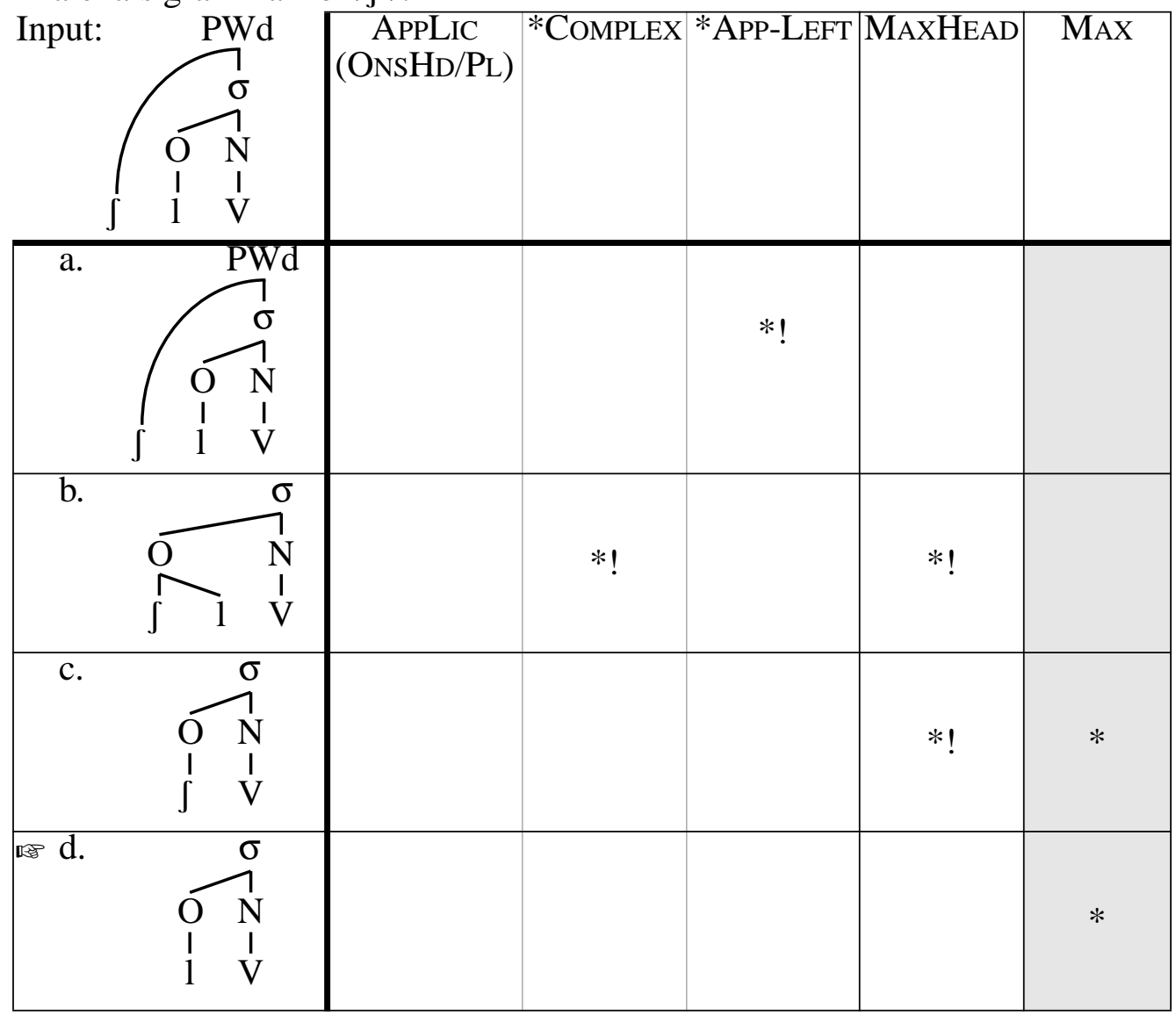

The final question we must address concerning $/ \int \mathrm{r} /$ is how the German-speaking child like Annalena ultimately arrives at the correct analysis for clusters of this shape. She cannot appeal to the absence of morpheme-internal / $\mathrm{r} /$ (cf. Section 4), as this would require access to indirect negative evidence. The adult analysis can only be arrived at through tidying up the grammar; that is, it must be driven by the learner's desire to treat all $/ \int /$-initial clusters in the same fashion on grounds of parsimony. This does not require indirect negative evidence, but it does require that the child undertake cross-form comparison with the other /S/-initial clusters. We leave further investigation of this issue to future research.

7 Is reference to heads truly necessary?

Our analysis of cluster reduction has provided an important role for highly-articulated prosodic representations and for constraints that make explicit reference to heads of syllable constituents, in particular MAXHEAD(ONSET). At the same time, we mentioned in the introduction that a recent trend observed in the constraint-based literature involves a move away from prosodic constituency in favour of phonetically-motivated explanations of phonological phenomena. The sonority pattern of cluster reduction would seem to offer support for the latter approach, as this 
pattern can be accounted for purely on phonetic grounds: no reference to sub-syllabic structure is required, as the consonant that survives can be determined solely by a set of constraints which assess the sonority value of syllable margins (see Barlow 1997, Gnanadesikan this volume). While, on the face of it, a structural approach to the head pattern would seem to be required, we have not yet demonstrated that a strictly linear analysis cannot work. In the following sections, we will argue that such an approach does not lead to satisfactory results for Amahl's grammar.

\subsection{Constraints against fricatives}

The approach that we will consider stems from the observation that (strident) fricatives emerge late in acquisition. Grijzenhout \& Joppen (in press) point out that, at early stages in development, many children avoid fricatives at the left-edge, whereas nasals and stops are favoured in this position. They capture these observations through the constraint Word ([-cont]. Grijzenhout \& Joppen focus primarily on German-speaking Naomi, a child we have listed in (3) as following the head pattern from 1;4.26-1;7.27. For us, Naomi falls into the head pattern on the basis of the following reductions: obstruent+liquid $\rightarrow$ stop, $/ \int /+$ stop $\rightarrow$ stop, and / //+nasal $\rightarrow$ nasal (recall from note 9 that she does not attempt / $1 /$ ). Grijzenhout \& Joppen take a different approach; they attribute Naomi's cluster reduction patterns to her general dislike for fricatives, that is, to highly-ranked ${ }_{\text {Word }}([$-cont $]$.

A similar analysis is provided for English-speaking Child 24 by Barlow \& Gierut (1999) at age 5;0 (this child is language-delayed). They propose that a constraint against /s/, *S, is undominated in Child 24's grammar, thereby ensuring that this segment never surfaces, whether in singleton onsets or in clusters, e.g. 'sun' $\rightarrow[\Lambda \mathrm{n}]$, 'swim' $\rightarrow$ [wIm]. Barlow \& Gierut further demonstrate that, at the next stage in development, age 5;3, singleton /s/ shows up as target-like, but /s/+C clusters still undergo /s/ deletion, an effect which is achieved through the ranking they provide in (31). (*COMPLEX is responsible for reduction of all types of clusters in their account.)

(31) Child 24 at age 5;3:

\begin{tabular}{|l|c|c|c|c|c|}
\cline { 3 - 6 } \multicolumn{2}{c|}{ a. $/ \mathrm{s} \Lambda \mathrm{n} /$} & MAX & $*$ S & *COMPLEX & ONSET \\
\hline & i. $[\mathrm{s} \Lambda \mathrm{n}]$ & & $*$ & & \\
\hline \multirow{3}{*}{ b. $/ \mathrm{swIm} /$} & i. $[\Lambda \mathrm{n}]$ & $*$ & & & $* !$ \\
\hline & ii. $[\mathrm{swIm}]$ & & $*$ & $* !$ & \\
& ii. $[\mathrm{sIm}]$ & $*$ & $* !$ & & \\
& iii. $[\mathrm{wIm}]$ & $*$ & & & \\
\hline
\end{tabular}

From the limited data provided in Barlow \& Gierut, Child 24 appears to follow the head pattern at age 5;3.32 Importantly, then, (31) demonstrates that we cannot reject an analysis of the

32. The data provided in Barlow (1997) on Child 24's other clusters (obstruent+liquid, /s/+stop, /s/+nasal) reveal that this is not the case, but this is tangential to the point being made here. 
head pattern which appeals to high-ranking *S, rather than to MAXHEAD(ONS), merely by observing a child who deletes /s/ only in clusters. We must therefore consider other evidence to tease apart the two approaches. In the next section, we demonstrate that evidence is available from Amahl's grammar to support the MAXHEAD approach.

\subsection{Amahl's grammar}

In the following lines, we address whether $* S$ can capture the cluster reductions observed in Amahl's outputs. Amahl has no fricatives at all in his productions until late in development; thus, on the face of it, it might seem that an appeal to the more general *FRIC would be able to capture his patterns of cluster reduction. In (3), we listed Amahl as following the head pattern from 2;2$2 ; 6$. At this point, all of his coronal fricatives are realised as stops, and all sub-coronal contrasts are neutralised: in initial position, coronal obstruents surface as [d], and somewhat later in development, as [t].

If Amahl's treatment of /s/-initial clusters were due to his general avoidance of (coronal) fricatives, we would expect to find that $/ \theta \mathrm{r} /$ and $/ \mathrm{fr} /$ pattern with $/ \mathrm{sl} /$ and $/ \mathrm{sw} /$ as concerns reduction. Specifically, / $\theta \mathrm{r} /$ and $/ \int \mathrm{r} /$ should surface as $[\mathrm{r}]$, alongside $/ \mathrm{sl} / \rightarrow[1]$ and $/ \mathrm{sw} / \rightarrow[\mathrm{w}]$. This, however, is not the case. While we admit that there is some variation in the data, the prevailing pattern is that the obstruent is retained in the case of $/ \theta \mathrm{r} /$ and $/ \int \mathrm{r} /$, while the approximant is retained in $/ \mathrm{sl} /$ and $/ \mathrm{sw} /$. As we have analysed the former as branching onsets and the latter as appendix-initial clusters, in both situations, it is the head of the cluster that is retained. The patterns observed can be seen most clearly in (32) (heads are underlined). ${ }^{33}$

(32) Summary of Amahl's cluster development (2;2-2;8.13)

\begin{tabular}{|c|c|c|c|c|c|c|c|}
\hline & & \multicolumn{3}{|c|}{ Preservation of head } & \multicolumn{3}{|c|}{ Preservation of non-head } \\
\hline \multicolumn{2}{|c|}{ Target Cluster } & Output & $\mathrm{N}$ & $\%$ & Output & $\mathrm{N}$ & $\%$ \\
\hline \multirow{2}{*}{$\begin{array}{l}\text { a. Branching } \\
\text { onset }\end{array}$} & $/ \underline{\theta} \mathrm{r} /$ & {$[\mathrm{d}, \mathrm{t}]$} & (8) & 67 & {$[\mathrm{r}, 1]$} & (4) & 33 \\
\hline & $/\lceil\mathrm{r} /$ & [d] & (2) & 67 & [в] & (1) & 33 \\
\hline \multirow{2}{*}{$\begin{array}{l}\text { b. Appendix- } \\
\text { initial }\end{array}$} & $/ \mathrm{s} \underline{1} /$ & [1] & (24) & 80 & [d] & $(6)$ & 20 \\
\hline & /sw/ & [w] & $(13)$ & 100 & [d] & (0) & 0 \\
\hline
\end{tabular}

If the absence of fricatives alone were driving Amahl's cluster reductions, we would expect all of the clusters in (32) to be treated in the same fashion. This is clearly not the case. Nevertheless, we cannot hastily conclude that reference to onset heads is necessary. We must first look at the interaction of *FRIC with other high-ranking constraints. Since we cannot exploit the fact that the clusters in (32b) begin with /s/ while those in (32a) do not (given that all coronal fricatives are realised as $[\mathrm{d}]$ ] on the surface), we must instead consider the quality of the second

33. The output segments in (32) abstract away from consonant harmony which applies in some of the data; however, one can always reconstruct what the target segments are in such forms. 
consonant. Since the sonority value of this consonant - rhotic versus lateral or glide - divides the patterns in (32) into two, the logical place to begin is with the interaction of *FRIC with sonoritybased constraints.

Concerning the latter, Prince \& Smolensky (ms) have proposed a fixed ranking of constraints which assess syllable margin well-formedness, following the schema $* \mathrm{M}(\mathrm{ARGIN}) / \lambda$. To ensure that the margin constraints treat Amahl's / $\mathrm{r} / \mathrm{differently} \mathrm{from} \mathrm{his} \mathrm{/sl/,} \mathrm{we} \mathrm{must} \mathrm{appeal} \mathrm{to} \mathrm{a}$ sonority difference between liquids, something which has been independently motivated by Kahn (1976) for English and by Hall (1992) for German. Building on this, we arrive at the partial ranking ...*M/Rнот > $>$ M/LAT... The tableau in (33) shows that if IDENT(cont), the constraint responsible for stop-fricative alternations (McCarthy \& Prince 1995), is ranked between $* \mathrm{M} / \mathrm{RHOT}$ and $* \mathrm{M} / \mathrm{LAT}$, the correct results obtain for target / $\theta \mathrm{r} /, / \int \mathrm{r} /$, and $/ \mathrm{sl} /$.

Coronal fricative + liquid clusters:

\begin{tabular}{|c|c|c|c|c|c|c|}
\hline & & & *FRIC & *M/RHOT & IDENT(cont) & $* \mathrm{M} / \mathrm{LAT}$ \\
\hline a. $/ \theta \mathrm{r} /$ & & i. $\theta$ & $* !$ & & & \\
\hline & 醂 & ii. $\mathrm{d}$ & & & $*$ & \\
\hline & & iii. $r$ & & $* !$ & & \\
\hline b. $/ \int \mathrm{r} /$ & & i. $\int$ & $* !$ & & & \\
\hline & 㖷 & ii. $\mathrm{d}$ & & & $*$ & \\
\hline & & 111. $r$ & & $* !$ & & \\
\hline c. $/ \mathrm{sl} /$ & & 1. $\mathrm{S}$ & $* !$ & & & \\
\hline & & ii. $\mathrm{d}$ & & & $* !$ & \\
\hline & & iii. 1 & & & & $*$ \\
\hline
\end{tabular}

However, a problem immediately arises when we attempt to extend the analysis to target /sw/. With the addition of *M/GLIDE to the hierarchy, we incorrectly predict that /sw/ should surface as [d], instead of [w], as demonstrated in (34).

(34) Coronal fricative + glide clusters:

\begin{tabular}{|l|c|c|c|c|c|c|}
\multicolumn{2}{|c|}{} & $*$ FRIC & $* \mathrm{M} /$ GLIDE & $* \mathrm{M} /$ RHOT & IDENT(cont) & $* \mathrm{M} / \mathrm{LAT}$ \\
\hline \multirow{5}{*}{ a. /sw/ } & i. $\mathrm{s}$ & $* !$ & & & & \\
\cline { 2 - 8 } & (*) ii. d & & & & $*$ & \\
\cline { 2 - 8 } & iii. $\mathrm{w}$ & & $* !$ & & & \\
\hline
\end{tabular}

What appears to be needed is a constraint, like *FRIC, that can be ranked independently of the margin constraints, *RHOт. If * Rнот were the constraint to dominate IDENT(cont) in place of $* \mathrm{M} / \mathrm{RHot}$, it could be ranked higher than the offensive *M/GLIDE, and the correct results would obtain. See (35). 
(35) Introducing *Rнот:

\begin{tabular}{|c|c|c|c|c|c|c|c|c|}
\hline \multirow{4}{*}{ a. $/ \theta \mathrm{r} /$} & & & *FRIC & *RHOT & IDENT(cont) & *M/GLIDE & *M/RHOT & $* \mathrm{M} / \mathrm{LAT}$ \\
\hline & & $\begin{array}{ll}\text { i. } & \theta\end{array}$ & $* !$ & & & & & \\
\hline & 舟 & ii. $\mathrm{d}$ & & & $*$ & & & \\
\hline & & iii. $r$ & & $* !$ & & & * & \\
\hline \multirow[t]{3}{*}{ b. $/ \int \mathrm{r} /$} & & i. $\quad \int$ & *! & & & & & \\
\hline & 果察 & ii. d & & & * & & & \\
\hline & & iii. $r$ & & $* !$ & & & * & \\
\hline \multirow[t]{3}{*}{ c. /sl/ } & & $\begin{array}{ll}\text { i. } & \mathrm{S}\end{array}$ & *! & & & & & \\
\hline & & ii. $\mathrm{d}$ & & & $* !$ & & & \\
\hline & 曲 & iii. 1 & & & & & & $*$ \\
\hline \multirow[t]{3}{*}{ d. /sw/ } & & $\begin{array}{ll}\text { i. } & \mathrm{s}\end{array}$ & $* !$ & & & & & \\
\hline & & ii. $\mathrm{d}$ & & & $* !$ & & & \\
\hline & 雨 & iii. $\mathrm{W}$ & & & & * & & \\
\hline
\end{tabular}

We have arrived at an analysis of Amahl's outputs that is descriptively adequate, but one which we reject nonetheless on grounds that it lacks explanatory adequacy. Prince \& Smolensky's $* \mathrm{M}(\mathrm{ARGIN}) / \lambda$ is designed to express sonority constraints on the shape of (left-edge) margins and, as such, the ranking is non-commutable: *M/GLIDE $>* \mathrm{M} / \mathrm{RHOT}>$ >M/LAT $>$ *M/NASAL $>$ *M/FrIC. An analysis of cluster reduction that appeals to high-ranking *FrIC and * RHOT circumvents this fixed ranking by exploiting their rankable equivalents. Our approach, by contrast, appeals to cross-linguistically supported facts about left-edge clusters to account for Amahl's treatment of /s/-initial clusters on the one hand versus fricative-initial clusters on the other. The segment that survives cluster reduction is not tied to the shape of Amahl's inventory of singleton consonants, but instead, arises from the structural relationships that these segments enter into.

\section{Conclusion}

In this paper, we have discussed two patterns of reduction for left-edge clusters that are observed in the acquisition of West Germanic languages. These patterns, which we called the sonority and head patterns, differ in their treatment of rising sonority /S/-initial clusters: in the sonority pattern, the least sonorous consonant is retained in output forms (e.g. /S1/ $\rightarrow[\mathrm{S}]$ ); in the head pattern, it is the sonorant that survives (e.g. /S1/ $\rightarrow[1]$ ), that is, the consonant that is the head of the onset in the target form.

We argued that the two patterns of cluster reduction are representative of distinct stages in development that differ in the degree to which inputs are elaborated, rather than differing in constraint ranking. We proposed that the head pattern, stage 2 in development, can best be accounted for if highly-structured target-like inputs are posited, while the sonority pattern, stage 
1, arises from inputs that are less articulated: only heads of sub-syllabic constituents are specified. At stage 1, there is no knowledge of the structural relations that hold across strings of consonants, and thus, the head of the onset can only be defined on the basis of relative prominence. This led to incorrect head selection for rising sonority /S/-initial clusters, clusters where the head in the target grammar is unexpectedly the segment of highest sonority.

Correct understanding of the head of a cluster requires that children take account of the distributional evidence available in the ambient language. In order to determine the type of evidence that is available, we systematically examined the distributional facts for the three languages under investigation. These facts support the view that all /S/-initial clusters, regardless of their sonority profile, are represented with a left-edge appendix. We argued that the sonority pattern child will be forced to take account of this evidence as s/he attempts to prosodify all of the segments in a cluster, on the way to achieving target-like inputs.

We demonstrated that a single ranking can be motivated for both patterns of cluster reduction if a constraint requiring faithfulness to the head of the onset constituent, MAXHEAD(Ons), is highly-ranked. The markedness constraints *COMPLEX and *APP-LEFT must be undominated, thereby ensuring that no clusters are realised on the surface. As we argued that the inputs for the two groups of children differ in terms of headedness, MAXHEAD(ONS) will appropriately select the consonant that survives from the input cluster.

Finally, our analysis has relied on the premise that children's inputs are built up through the course of acquisition until they reach the target stage when inputs are fully prosodified. While we provided some evidence from Brazilian Portuguese for fully prosodified inputs in adult grammars, the implications of such a proposal have not been thoroughly explored. We leave this to future research. 


\section{References}

Alderete, J. (1995). Faithfulness to prosodic heads. Paper presented at The Derivational Residue in Phonology Conference, Tilburg University.

Barlow, J. (1997). A constraint-based account of syllable onsets: evidence from developing systems. $\mathrm{PhD}$ dissertation, Indiana University.

Barlow, J. (1999). An argument for adjuncts: evidence from a phonologically disordered system. In A. Greenhill, H. Littlefield \& C. Tano (eds.) Proceedings of the 23rd Annual Boston University Conference on Language Development. Somerville, Mass.: Cascadilla Press. 4455.

Barlow, J. \& J. Gierut (1999). Optimality theory in phonological acquisition. Journal of Speech, Language, and Hearing Research 42. 1482-1498.

Bernhardt, B.H. \& J.P. Stemberger (1998). Handbook of phonological development from the perspective of constraint-based nonlinear phonology. San Diego: Academic Press.

Booij, G. (1995). The phonology of Dutch. Oxford: Clarendon Press.

Charette, M. (1991). Conditions on phonological government. Cambridge: Cambridge University Press.

Chin, S.B. (1996). The role of the sonority hierarchy in delayed phonological systems. In T.W. Powell (ed.) Pathologies of speech and language: contributions of clinical phonetics and linguistics. New Orleans: International Clinical Phonetics and Linguistics Association. 109117.

Chin, S.B. and D.A. Dinnsen (1992). Consonant clusters in disordered speech: constraints and correspondence patterns. Journal of Child Language 19. 259-285.

Chomsky, N. (1981). Lectures on government and binding. Dordrecht: Foris.

Chomsky, N. \& M. Halle (1968). The sound pattern of English. New York: Harper \& Row.

Clements, G.N. (1990). The role of the sonority cycle in core syllabification. In J. Kingston \& M.E. Beckman (eds.) Papers in laboratory phonology I: between the grammar and physics of speech. Cambridge: Cambridge University Press. 283-333.

Côté, M.-H. (2000) Consonant cluster phonotactics: a perceptual approach. $\mathrm{PhD}$ dissertation, MIT.

Demuth, K. (1995). Markedness and the development of prosodic structure. NELS 25. 13-25.

Elsen, H. (1991). Erstspracherwerb: der Erwerb des deutschen Lautsystems. Wiesbaden: Deutscher Universitäts-Verlag.

Ewen, C. (1982). The internal structure of complex segments. In van der Hulst \& Smith (1982: part 2). 27-67.

Ferguson, C.A. \& C.B. Farwell (1975). Words and sounds in early language acquisition. Language 51. 419-439.

Fikkert, P. (1994). On the acquisition of prosodic structure. $\mathrm{PhD}$ dissertation, Leiden University/HIL. Published 1994, The Hague: Holland Academic Graphics. 
Fudge, E. (1969). Syllables. JL 5. 193-320.

Giegerich, H. (1985). Metrical phonology and phonological structure. Cambridge: Cambridge University Press.

Giegerich, H. (1992). English phonology. Cambridge: Cambridge University Press.

Gierut, J. (1999). Syllable onsets: clusters and adjuncts in acquisition. Journal of Speech Language and Hearing Research 42. 708-726.

Gilbers, D. \& D.-B. Den Ouden (1994). Compensatory lengthening and cluster reduction in first language acquisition: a comparison of different analyses. In A. de Boer, H. de Hoop \& H. de Swart (eds.) Language and Cognition 4: Yearbook 1994 of the Research Group for Theoretical and Experimental Linguistics. University of Groningen. 69-82.

Gnanadesikan, A.E. (this volume). Markedness and faithfulness constraints in child phonology.

Goad, H. (1996). Consonant harmony in child language: evidence against coronal underspecification. In B. Bernhardt, J. Gilbert \& D. Ingram (eds.) Proceedings of the UBC International Conference on Phonological Acquisition. Somerville, Mass.: Cascadilla Press. 187-200.

Goad, H. (1997). Consonant harmony in child language: an optimality-theoretic account. In S.J. Hannahs \& M. Young-Scholten (eds.) Focus on phonological acquisition. Amsterdam: John Benjamins. 113-142.

Goad, H. (in press). Assimilation phenomena and initial constraint ranking in early grammars. In H.-J. A. Do, L. Dominguez \& A. Johansen (eds.) Proceedings of the 25th Annual Boston University Conference on Language Development. Somerville, Mass.: Cascadilla Press.

Goad, H. \& K. Brannen (to appear). Phonetic evidence for phonological structure in syllabification. In J. van de Weijer, V. van Heuven \& H. van der Hulst (eds.) Issues in the phonetics-phonology interface. Amsterdam: John Benjamins.

Grijzenhout, J. \& S. Joppen (in press). The lack of onsets in German child phonology. In I. Lasser (ed.) The process of language acquisition. Frankfurt/Berlin: Peter Lang Verlag.

Hale, M. \& C. Reiss (1998). Formal and empirical arguments concerning phonological acquisition. LI 29. 656-683.

Hall, T.A. (1992). Syllable structure and syllable-related processes in German. Tübingen: Max Niemeyer Verlag.

Hamilton, P. (1996). Phonetic constraints and markedness in the phonotactics of Australian Aboriginal languages. $\mathrm{PhD}$ dissertation, University of Toronto.

Harris, J. (1994). English sound structure. Oxford: Blackwell.

Harris, J. (1997). Licensing inheritance: an integrated theory of neutralisation. Phonology 14. 315-370.

Hulst, H. van der \& N. Smith (eds.) (1982). The structure of phonological representations. 2 parts. Dordrecht: Foris.

Hulst, H. van der (1984). Syllable structure and stress in Dutch. Dordrecht: Foris. 
Humbert, H. (1997). On the asymmetrical nature of nasal obstruent relations. NELS 27. 219-233. Ingram, D. (1989). Phonological disability in children. 2nd edn. London: Cole \& Whurr.

Inkelas, S. (1994). The consequences of optimization for underspecification. Ms, University of California, Berkeley.

Itô, J. (1986). Syllable theory in prosodic phonology. $\mathrm{PhD}$ dissertation, University of Massachusetts Amherst. Published 1988, New York: Garland.

Itô, J. \& R.A. Mester (1997). Sympathy Theory and German truncations. Ms, University of California Santa Cruz.

Itô, J., Y. Kitagawa \& R.A. Mester (1996). Prosodic faithfulness and correspondence: evidence from a Japanese argot. Ms, University of California Santa Cruz.

Jakobson, R. (1941). Child language, aphasia and phonological universals. The Hague: Mouton. Translated 1968, A.R. Keiler.

Jongstra, W. (2000) Variability in the acquisition of word-initial consonant clusters. Ms., University of Toronto.

Kager, R. \& W. Zonneveld (1985/86). Schwa, syllables, and extrametricality in Dutch. The Linguistic Review 5. 197-221.

Kahn, D. (1976). Syllable-based generalizations in English phonology. PhD dissertation, MIT. Published 1980, New York: Garland.

Kaye, J. (1985). On the syllable structure of certain West African languages. In D. Goyvaerts (ed.) African linguistics: essays in memory of M.W.K. Semikenke. Amsterdam: John Benjamins. 285-308.

Kaye, J. (1990). 'Coda' licensing. Phonology 7. 301-330.

Kaye, J. (1992). Do you believe in magic? The story of $s+C$ sequences. SOAS Working Papers in Linguistics 2. 293-313.

Kaye, J., J. Lowenstamm \& J.-R. Vergnaud (1990). Constituent structure and government in phonology. Phonology 7. 193-231.

Kenstowicz, M. (1994). Phonology in generative grammar. Oxford: Blackwell.

Kochetov, A. (1999). Constraints on distribution of palatalized stops: Evidence for licensing by cue. In P. Tamanji, M. Hirotani \& N. Hall (eds.) Proceedings of the North East Linguistic Society 29. 167-181. University of Massachusetts, Amherst: GLSA.

Lebel, É. (1998). On first language acquisition of word-initial English clusters: a case study. MA Thesis, McGill University.

Levin, J. (1985). A metrical theory of syllabicity. PhD dissertation, MIT.

Lleó, C. \& M. Prinz (1996). Consonant clusters in child phonology and the directionality of syllable structure assignment. Journal of Child Language 23. 31-56.

Lohuis-Weber, H. \& W. Zonneveld (1996). Phonological acquisition and Durtch word prosody. Language Acquisition 5. 245-283. 
Macken, M. (1980). The child's lexical representation: the 'puzzle-puddle-pickle' evidence. $J L$ 16. 1-17.

McCarthy, J.J. (1997). Faithfulness in prosodic morphology and phonology: Rotuman revisited. Ms, University of Massachusetts Amherst.

McCarthy, J.J. \& A.S. Prince (1995). Faithfulness and reduplicative identity. University of Massachusetts Occasional Papers 18. 249-384.

Mester, R.A. \& J. Itô (1989). Feature predictability and underspecification: palatal prosody and Japanese mimetics. $\operatorname{Lg}$ 64. 258-293.

Miller, W.R. (1965). Acoma grammar and texts. Berkeley and Los Angeles: University of California Press.

Nikièma, E. (1999). Government-licensing and consonant cluster simplification in Quebec French. Canadian Journal of Linguistics 44. 327-357.

Ohala, D. (1999). The influence of sonority on children's cluster reductions. Journal of Communication Disorders 32. 397-422.

Pater, J. (1997). Minimal violation and phonological development. Language Acquisition 6. 20153.

Pater, J. (2000). Non-uniformity in English secondary stress: the role of ranked and lexically specific constraints. Phonology 17. 237-274.

Pater, J. (this volume). Bridging the gap between receptive and productive development with minimally violable constraints.

Piggott, G.L. (1991). Apocope and the licensing of empty-headed syllables. The Linguistic Review 8. 287-318.

Pinker, S. (1984). Language learnability and language development. Cambridge, Mass.: Harvard University Press.

Prince, A.S. \& P. Smolensky (1993). Optimality Theory: constraint interaction in generative grammar. Ms, Rutgers University \& University of Colorado.

Rice, K. (1992). On deriving sonority: a structural account of sonority relationships. Phonology 9. 61-99.

Rose, S. (1997). Theoretical issues in comparative Ethio-Semitic phonology and morphology. PhD dissertation, McGill University.

Rose, Y. (1999). A structural account of Root node deletion in loanword phonology. Canadian Journal of Linguistics 44. 359-404.

Rose, Y. (2000). Headedness and prosodic licensing in the L1 acquisition of phonology. $\mathrm{PhD}$ dissertation, McGill University.

Schwartz, R.G. \& L.B. Leonard (1982). Do children pick and choose? An examination of phonological selection and avoidance. Journal of Child Language 9. 319-336.

Selkirk, E.O. (1982). The syllable. In van der Hulst \& Smith (1982: part 2). 337-383.

Sherer, T. (1994). Prosodic phonotactics. PhD dissertation, University of Massachusetts Amherst. 
Smith, N.V. (1973). The acquisition of phonology: a case study. Cambridge: Cambridge University Press.

Smolensky, P. (1996). The comprehension/production dilemma in child language. LI 27. 720731.

Spencer, A. (1986). Towards a theory of phonological development. Lingua 68. 3-38.

Stampe, D. (1969). The acquisition of phonetic representation. CLS 5. 433-444.

Stoel-Gammon, C. \& J.A. Cooper (1984). Patterns of early lexical and phonological development. Journal of Child Language 11. 247-271.

Steriade, D. (1982). Greek prosodies and the nature of syllabification. $\mathrm{PhD}$ dissertation, MIT.

Steriade, D. (1999). Phonetics in phonology: the case of laryngeal neutralization. In M.K. Gordon (ed.) UCLA Working Papers in Linguistics: Papers in Phonology 3: 25-246.

Torre, E.J. van der (2001). Asymmetries within obstruent-liquid clusters. Paper presented at the Montréal-Ottawa-Toronto Phonology Workshop, University of Ottawa.

Treiman, R., J. Gross \& A. Glavin (1992). The syllabification of /s/ clusters in English. Journal of Phonetics 20. 383-402.

Trommelen, M. (1984). The syllable in Dutch: with special reference to diminutive formation. Dordrecht: Foris Publications.

Velten, H.V. (1943). The growth of phonemic and lexical patterns in infant language. $\operatorname{Lg} 19$. 281-292.

Vennemann, T. (1982). Zur Silbenstruktur der deutschen Standardsprache. In T. Vennemann (ed.) Silben, Segmente, Akzente. Tübingen: Max Niemeyer Verlag. 261-305.

Waals, J. (1999). An experimental view of the Dutch syllable. PhD dissertation, Utrecht University/HIL. Published 1999, The Hague: Holland Academic Graphics.

Weijer, J. van de (1996). Segmental structure and complex segments. Tübingen: Max Niemeyer Verlag.

Wiese, R. (1988). Silbische und lexikalische Phonologie: Studien zum Chinesischen und Deutschen. Tübingen: Max Niemeyer Verlag.

Wiese, R. (1996). The phonology of German. Oxford: Clarendon Press.

Wright, R.A. (1996). Consonant clusters and cue preservation in Tsou. PhD dissertation, University of California, Los Angeles.

Zonneveld, W. (1993). Schwa, superheavies, stress and syllables in Dutch. The Linguistic Review 10. 61-100. 